Marquette University

e-Publications@Marquette

Biological Sciences Faculty Research and

Publications

Biological Sciences, Department of

$1-2016$

\title{
Cryptic Lineages and Diversification of an Endemic Anole Lizard (Squamata, Dactyloidae) of the Cerrado Hotspot
}

\author{
Carlos E. Guarnizo \\ Universidade de Brasília \\ Fernanda P. Werneck \\ Instituto Nacional de Pesquisas da Amazônia \\ Lilian G. Giugliano \\ Universidade de Brasília \\ Marcella G. Santos \\ University of Mississippi \\ Jéssica Fenker \\ Universidade de Brasília
}

See next page for additional authors

Follow this and additional works at: https://epublications.marquette.edu/bio_fac

Part of the Biology Commons

\section{Recommended Citation}

Guarnizo, Carlos E.; Werneck, Fernanda P.; Giugliano, Lilian G.; Santos, Marcella G.; Fenker, Jéssica; Sousa, Lucas; D;Angiolella, Annelise B.; Dos Santos, Adriana R.; Strussmann, Christine; Rodrigues, Miguel T.; Dorado-Rodrigues, Tainá F.; Gamble, Tony; and Colli, Guarino R., "Cryptic Lineages and Diversification of an Endemic Anole Lizard (Squamata, Dactyloidae) of the Cerrado Hotspot" (2016). Biological Sciences

Faculty Research and Publications. 754.

https://epublications.marquette.edu/bio_fac/754 


\section{Authors}

Carlos E. Guarnizo, Fernanda P. Werneck, Lilian G. Giugliano, Marcella G. Santos, Jéssica Fenker, Lucas

Sousa, Annelise B. D;Angiolella, Adriana R. Dos Santos, Christine Strussmann, Miguel T. Rodrigues, Tainá

F. Dorado-Rodrigues, Tony Gamble, and Guarino R. Colli 
Marquette University

e-Publications@Marquette

\section{Biological Sciences Faculty Research and Publications/College of Arts and Sciences}

This paper is NOT THE PUBLISHED VERSION; but the author's final, peer-reviewed manuscript. The published version may be accessed by following the link in the citation below.

Molecular Phylogenetics and Evolution, Vol. 94, No. A (January 2016) : 279-289. DOI. This article is (C) Elsevier and permission has been granted for this version to appear in e-Publications@Marquette. Elsevier does not grant permission for this article to be further copied/distributed or hosted elsewhere without the express permission from Elsevier.

\section{Cryptic Lineages and Diversification of an Endemic Anole Lizard (Squamata, Dactyloidae) of the Cerrado Hotspot}

\section{Carlos E. Guarnizo}

Departamento de Genética e Morfologia, Instituto de Ciências Biológicas, Universidade de Brasília, 70910-900 Brasília, Distrito Federal, Brazil

Fernanda P. Werneck

Programa de Coleções Científicas Biológicas, Coordenação de Biodiversidade, Instituto Nacional de Pesquisas da Amazônia, 69060-000 Manaus, Amazonas, Brazil

Lilian G. Giugliano

Departamento de Genética e Morfologia, Instituto de Ciências Biológicas, Universidade de Brasília, 70910-900 Brasília, Distrito Federal, Brazil

Marcella G. Santos

Department of Biology, University of Mississippi, University, MS

Jéssica Fenker 
Departamento de Zoologia, Instituto de Ciências Biológicas, Universidade de Brasília, 70910-900 Brasília, Distrito Federal, Brazil

\section{Lucas Sousa}

Departamento de Genética e Morfologia, Instituto de Ciências Biológicas, Universidade de Brasília, 70910-900 Brasília, Distrito Federal, Brazil

\section{Annelise B. D' Angiolella}

Programa de Pós-graduação em Zoologia, Museu Paraense Emílio Goeldi/CZO, C.P. 399, 66017-970 Belém, Pará, Brazil

\section{Adriana R. dos Santos}

Departamento de Genética e Morfologia, Instituto de Ciências Biológicas, Universidade de Brasília, 70910-900 Brasília, Distrito Federal, Brazil

\section{Christine Strüssmann}

Departamento de Ciências Básicas e Produção Animal, Faculdade de Agronomia, Medicina Veterinária e Zootecnia, Universidade Federal de Mato Grosso, 78060-900 Cuiabá, Mato Grosso, Brazil

\section{Miguel T. Rodrigues}

Laboratório de Herpetologia, Departamento de Zoologia, Instituto de Biociências, Universidade de São Paulo, 05508-090 São Paulo, Brazil

\section{Tainá F. Dorado-Rodrigues}

Programa de Pós-graduação em Ecologia e Conservação da Biodiversidade, Universidade Federal de Mato Grosso, 78060-900 Cuiabá, Mato Grosso, Brazil

\section{Tony Gamble}

Department of Genetics, Cell Biology and Development, \& Bell Museum of Natural History, University of Minnesota, Minneapolis, MN

\section{Guarino R. Colli}

Departamento de Zoologia, Instituto de Ciências Biológicas, Universidade de Brasília, 70910-900 Brasília, Distrito Federal, Brazil

\section{Highlights}

- The nominal species $N$. meridionalis is not a single species, but a complex of at least five cryptic species.

- Divergence time within the N. meridionalis complex is old, splitting back into the early-mid Miocene.

- The topographic reorganization during the Miocene was an important factor in promoting genetic divergence.

- Lineages within the $N$. meridionalis complex show evidence for non-stationary isolation by distance.

- Niche conservatism seems to be an important mechanism that promoted geographic fragmentation in the group.

\section{Abstract}

The Cerrado is a wide Neotropical savanna with tremendously high endemic diversity. Yet, it is not clear what the prevalent processes leading to such diversification are. We used the Cerrado-endemic lizard Norops meridionalis to investigate the main abiotic factors that promoted genetic divergence, the timings of these divergence events, and how these relate to cryptic diversity in the group. We sequenced mitochondrial and 
nuclear genes from 21 sites of $N$. meridionalis to generate species tree, divergence time estimations, and estimate species limits. We also performed population-level analysis and estimated distribution models to test the roles of niche conservatism and divergence in the group diversification. We found that $N$. meridionalis is composed by at least five cryptic species. Divergence time estimations suggest that the deepest branches split back into the early-mid Miocene, when most of the geophysical activity of the Cerrado took place. The deep divergences found in N. meridionalis suggest that beta anoles invaded South America much earlier than previously thought. Recent published evidence supports this view, indicating that the Panama gap closed as early as 15 mya, allowing for an early invasion of Norops into South America. The spatial pattern of diversification within N. meridionalis follows a northwest-southeast direction, which is consistent across several species of vertebrates endemic to the Cerrado. Also, we found evidence for non-stationary isolation by distance, which occurs when genetic differentiation depends on space. Our preliminary data in two out of five lineages suggest that niche conservatism is an important mechanism that promoted geographic fragmentation in the group.

\section{Graphical abstract}

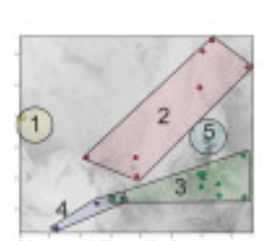

N. meridionalis is a complex of at least five cryptic species.

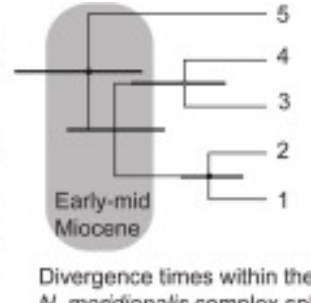

N. menidionalis complex split back into the early-mid

Miocene, suggesting that

beta anoles invaded South

America much earlier than previously thought.

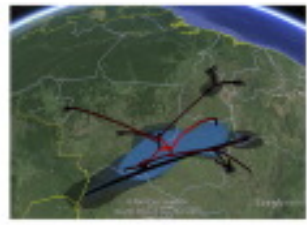

The topographic reorganization during the Miocene was an important factor in promoting genetic divergence within

N. menidionails.

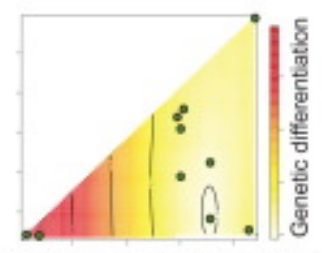

Lineages within $N$. meridionalls display non-stationary in isolation by distance. Niche conservatism might have promoted geographic fragmentation.

\section{Keywords}

Phylogeography, Species delimitation, Speciation, Savanna, Miocene, Norops

\section{Introduction}

The South American Cerrado is a vast tropical savanna that, despite an apparent uniformity in appearance, is characterized by a rich, endemic and threatened biota (Myers et al., 2000, Nogueira et al., 2011). Despite its recognition as a biodiversity hotspot, there is no consensus on which mechanisms mainly promoted species diversification. Some of the non-mutually exclusive hypotheses to explain the Cerrado diversity (Colli et al., 2005, Werneck, 2011) include: (a) the plateau/depression hypothesis, which suggests old shields in the Brazilian Plateau (that uplifted during the late Tertiary) were separated by younger depressions (expanded by erosive processes during the Quaternary), resulting in older lineages associated with plateaus and younger lineages associated with depressions; (b) the marine transgressions hypothesis, which suggests that cycles of marine transgressions into the Paraná basin in the middle and late Miocene promoted extensive flooding of lowlands, isolating and differentiating highland populations and causing the extinction of lowland populations and a subsequent recolonization; and (c) the Pleistocene refuge hypothesis, which suggests that genetic diversity should be higher in regions of higher stability (refugia) during Pleistocene climatic fluctuations.

Recent molecular studies have found that different mechanisms are responsible for the diversification of different taxonomic groups in Cerrado. For instance, some groups support the effect of old events such as the final uplift of the Central Brazilian Plateau (Domingos et al., 2014, Werneck et al., 2012a), or the late Tertiary marine transgressions on diversification patterns (Garda and Cannatella, 2007, Giugliano et al., 2013, Werneck et al., 2009), while others support the role of recent Quaternary cycles (Ramos et al., 2007). In some taxa, diversification can also be explained by both old and recent events (Maciel et al., 2010, Prado et al., 2012). 
Furthermore, climatic stability may be a good predictor of squamate species richness (Werneck et al., 2012d), while other studies have found a lack of correlation between climatic stability and levels of genetic diversity or main phylogeographical patterns (Magalhaes et al., 2014, Pinheiro et al., 2013, Santos et al., 2014).

One explanation for the fact that different studies on Cerrado biodiversity support different hypotheses is that most of these studies were carried out at different temporal, spatial, and taxonomic scales. The temporal scale can be fundamental in explaining diversity patterns in opposite ways. For instance, regional community species composition and deep phylogenetic splits are more likely to depend on long-term processes such as speciation, extinction, and migration (Ricklefs, 1987). On the other hand, short temporal scales can have more explanatory power when addressing below-species diversity patterns, such as intraspecific genetic diversity and divergence, which mostly are dependent on ecological factors such as niche width and niche conservatism (GómezRodríguez et al., 2014, Wiens, 2004), dispersal abilities (Ghalambor et al., 2006), and environmental heterogeneity (Garrick, 2010, Guarnizo and Cannatella, 2013). The spatial (or geographic) and taxonomic scales of a study may also have profound effects on the diversity patterns detected (Wiens, 1989). Above the specieslevel, the larger the geographic sampling scheme, the more diversity will be encountered. Below the specieslevel, genetic variation is often larger when species are sampled throughout their geographical range compared with a more restricted geographic sampling (Bergsten et al., 2012). Ignoring the effects of differing temporal, spatial, and taxonomic scales when comparing regional diversification studies can be problematic, because at first glance what appears to be conflicting mechanisms might in fact be congruent processes seen from different temporal and spatial perspectives. Intraspecific genetic analyses of widely distributed species are fundamental if the goal is to understand the processes that explain the Cerrado diversification, because the effects of both geographic and temporal scale of diversification can be tested in a single study.

Anole lizards have been used as model organisms to evaluate the response of intraspecific genetic diversification to ecological pressures and allopatric events at multiple geographic and temporal scales, mainly in Caribbean island systems (Calsbeek et al., 2007, Hertz et al., 2013, Losos, 2009, Thorpe et al., 2010). Literature on the diversification of mainland South American anoles is scarcer, but previous work has addressed deep phylogenetic relationships (Castañeda and De Queiroz, 2011, Prates et al., 2014) and recently diversified groups of rainforest species (Glor et al., 2001). The taxonomy of anoles has been a topic of dissension (Castañeda and De Queiroz, 2013, Nicholson et al., 2012, Poe, 2013) and we choose to recognize Norops as a separate genus, which may lead to a deeper understanding and greater appreciation of the diversity within anoles (Nicholson et al., 2014).

Norops meridionalis Boettger 1885 is a small, endemic anole lizard originally described from Paraguay and also recorded in open areas in the Cerrado biome of Brazil and Bolivia (Langstroth, 2006, Nogueira et al., 2011, Vanzolini and Williams, 1970). Characterized by cryptic coloration and behavior, very little is known about its ecology (Costa et al., 2013, Gainsbury and Colli, 2003, Gainsbury and Colli, 2014, Nogueira et al., 2005, Vitt, 1991, Vitt and Caldwell, 1993). Perhaps because of its cryptic appearance, we are still ignorant about its potential distribution, biogeographic origin, and the patterns and processes that explain its intraspecific genetic variation. The wide geographic distribution of $N$. meridionalis makes it an ideal model to explore the main factors that promoted intraspecific genetic variation at different temporal and geographic scales in the Cerrado region.

Here we used mitochondrial and nuclear datasets to evaluate the following non-exclusive hypotheses and corresponding predictions regarding the temporal and spatial processes that may have influenced the diversification and distribution of $N$. meridionalis:

1. At broader temporal and geographical scales, the genetic divergence in N. meridionalis is explained by old Tertiary geologic, orographic, and climatic events. This hypothesis predicts that the timing of major 
divergences within the species will coincide with the final uplift of the Central Brazilian Plateau or the marine transgressions during the Neogene. Further, we expect that a prolonged geographic isolation of populations promoted genetic diversity within N. meridionalis. At narrower temporal and geographic scales, we expect support for an association between intraspecific genetic variation and climatic/topographic heterogeneity.

2. Rather than old processes, genetic divergence in N. meridionalis at wide geographic scales is explained by recent climatic cycles during the Pleistocene. Here, we expect divergence times between major clades not to be older than 2 million years (my), independent of the geographic distance between populations, and strong discordance between genetic variation and the geographic distribution of populations.

3. Allopatric speciation due to niche conservatism (i.e. maintenance of niche preferences through time), rather than niche divergence (Wiens and Graham, 2005), explains major diversification within $N$. meridionalis because populations were unable to adapt to novel conditions generated by the Neogene topographic dynamics, promoting the appearance of geographic barriers to gene flow. This hypothesis predicts climatic properties between highly divergent clades from disjunct geographic areas to be more similar than expected by chance. Also, we expect to find non-stationary patterns of isolation by distance, which occurs when the rate at which genetic differentiation between individuals accumulates with distance depends on space due to factors such as the existence of barriers to gene flow (DuforetFrebourg and Blum, 2014).

\section{Materials and methods}

\subsection{DNA sequencing}

We included 84 tissue samples of N. meridionalis from 21 sites in the Brazilian Cerrado (Fig. 1). DNA samples were obtained from specimens deposited primarily at the Coleção Herpetológica da Universidade de Brasília (CHUNB) and other Brazilian collections (Table S1 for museum numbers, geographic coordinates, and GenBank accession numbers. Sequence alignments can be accessed in the TreeBase dataset link http://purl.org/phylo/treebase/phylows/study/TB2:S18051). We extracted total DNA from liver tissue with a MagMax Kit (Life Technologies, Grand Island, NY, USA), following the manufacturer's protocol. We amplified by polymerase chain reaction (PCR) and sequenced for all individuals a fragment of the mitochondrial NADH dehydrogenase 2 (ND2) gene, consisting of $1044 \mathrm{bp}$. We complemented the mitochondrial information by sequencing fragments of three nuclear genes, totaling four loci and $2830 \mathrm{bp}$ : the prolactin receptor (PRL) gene, consisting of $573 \mathrm{bp}$; the natural killer cell triggering receptor (NKTR) gene, consisting of $633 \mathrm{bp}$; and the nerve growth factor beta polypeptide (NGFB) gene, consisting of $580 \mathrm{bp}$. Due to problems with PCR, not all individuals were successfully sequenced for all four loci. Primers and PCR protocols are depicted in supplementary materials (Table S2). Sanger sequencing was conducted by Macrogen Inc. (Seoul, Korea). Chromatograms were assembled and inspected by eye using Geneious Pro 5.4.7 (Geneious Co., Wellington, New Zealand).
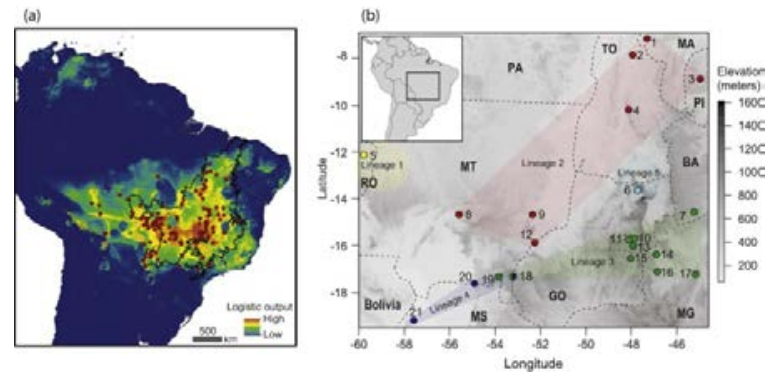

Fig. 1. Species distribution model and sampling sites of Norops meridionalis. (a) Species distribution model of the nominal species Norops meridionalis. Warmer colors indicate higher probabilities of occurrence. Red dots indicate the localities used to generate the species distribution model. (b) Sampling sites of $N$. meridionalis depicted in a topographic map of the 
Brazilian Cerrado biome in the states of BA - Bahia, GO - Goiás, MA - Maranhão, MG - Minas Gerais, MS - Mato Grosso do Sul, MT - Mato Grosso, PA - Pará, PI - Piauí, RO - Rondônia, and TO - Tocantins. Colors of sampling localities correspond to candidate species in Fig. 2. Numbers are map codes depicted in Table S1. Sampling localities with two colors correspond to localities where two different lineages co-occur in syntopy. Minimum convex polygons indicate the potential geographic range of each of the five highly genetically divergent lineages discovered here. (For interpretation of the references to color in this figure legend, the reader is referred to the web version of this article.)

\subsection{Gene tree, species tree, divergence times, and spatiotemporal phylogeography}

To test our first and second hypotheses (old vs. young events promoting genetic divergence within $N$. meridionalis) we estimated gene genealogies, species trees, and divergence times based on single-genes and partitioned concatenated alignments (mitochondrial and nuclear DNA). Gene genealogies were based on Bayesian inference (BI), using MrBayes 3.1.2 (Ronquist and Huelsenbeck, 2003). The Akaike information criterion (Akaike, 1974), implemented in jModelTest 2.1.7 (Darriba et al., 2012), was used to select the optimal nucleotide substitution model for each gene in the partitioned analysis (models selected for each gene were ND2: GTR+I+G, NKTR: HKY+I, NGFB: $\mathrm{K} 80+\mathrm{G}$, and PRL: GTR+I). We generated two runs of 10 million generations with the Metropolis-coupled Markov chain Monte Carlo (MCMC) algorithm. Each run contained four incrementally heated Markov chains (temperature 0.05), sampled every 1000 generations. Convergence of the two runs was assumed when the average standard deviation of the split frequencies was less than 0.01 . We contrasted our BI analysis with a partitioned maximum likelihood inference (ML) using RAxML version 8.0 (Stamatakis, 2006), using a GTRGAMMA model of evolution and a standard heuristic search with 1000 presudoreplicates. To root the ML and BI trees, we used N. chrysolepis (GeneBank accession numbers JN191537 and JN191530) and N. cf. tandai (AF337807). Additionally, we used the species within the chrysolepis species group sequenced by D’Angiolella et al. (2011) - N. tandai, N. brasiliensis, N. planiceps, N. scypheus, and N. bombiceps - to root a tree using the ND2 gene (Fig. S1).

The species tree and divergence times for $N$. meridionalis were based on the four loci under a coalescent model using *BEAST v2.1.3 (Drummond and Rambaut, 2007). We used a Yule tree prior, uncorrelated lognormal relaxed clocks, and calibrated the time estimates using a normal prior distribution on the mtDNA global substitution rate (mean $=0.0065$ substitutions $/ \mathrm{my} ; \mathrm{SD}=0.0025)$ following commonly used estimates for lizards of $0.65 \%$ changes/my (Macey et al., 1998). Substitution rates for the three nuclear markers were estimated relative to the mtDNA rate using a gamma prior for ucld.mean with default values, and exponential prior for ucld.stdev, with a mean of 0.5. We performed five independent runs of 100 million generations each, sampled at every 10,000 steps, totaling a posterior distribution of 10,000 trees/run. To assess stationary posterior distributions, effective sample sizes (ESS) above 200, and convergence between runs, we examined parameter traces with Tracer v1.6 (Rambaut et al., 2014). We estimated the species tree following the group assignment provided by the Bayesian genetic clustering analyses (BAPS) described below. We combined trees and log files after removing a burn-in of 10\% with Log Combiner v1.7.5 (Drummond and Rambaut, 2007) and subsequently annotated the combined tree files with TreeAnnotator v1.7.5 (Drummond and Rambaut, 2007) to calculate the maximum clade credibility (MCC) species tree.

Because our first and second hypotheses have a geographic component, we also reconstructed the diffusion history within Norops meridionalis under a continuous spatiotemporal Bayesian approach with BEAST v1.7.5. We employed the mtDNA data set based on unique haplotypes $(n=71)$ and applied a lognormal relaxed random walk (RRW) model, which is a time-heterogeneous approach that allows for heterogeneous diffusion rates across the branches of the phylogeny (Lemey et al., 2010), to infer the geographic location of ancestors and the diffusion of lineages continuously over space and time while accommodating for genealogical uncertainty. We implemented the same set of priors for the mtDNA substitution rates as described above and applied the Jitter option on multivariateTraitLikelihood to add a random noise to identical 
coordinates samples. We performed five independent runs of 100 million generations each, sampled at every 10,000 steps, assessed parameter traces with Tracer v1.6 (Rambaut et al., 2014), annotated tree files with Log Combiner v1.7.5, and computed the MCC tree with TreeAnnotator v1.7.5 (Drummond and Rambaut, 2007). We then generated a visual representation of the lineages diffusion across space and time for Google Earth using the Continuous Tree module of SPREAD v1.0.7 (Bielejec et al., 2011).

\subsection{Genetic clustering algorithms and species delimitation}

Because our first hypothesis predicts that old genetic divergence events would promote diversification within $N$. meridionalis, we performed a Bayesian population mixture analysis implemented in BAPS v. 4.13 (Corander et al., 2006) to identify highly divergent genetic groups that might correspond to potential cryptic species. We conducted the mixture analysis of individuals using the four-gene concatenated alignment and the geographic origin of the samples used as a prior. We ran BAPS with the maximal number of groups $(K)$ set to $2-10$.

We contrasted the groups found by BAPS with a species delimitation approach using BPP v. 3.0 (Yang and Rannala, 2010). The species tree generated by *BEAST was used as guide tree for all BPP analyses. We conducted three prior distribution schemes for ancestral population size $(\vartheta)$ and root age $(\tau)$ (Leaché and Fujita, 2010) to take into account three types of speciation histories: small population size/shallow divergence, large population size/deep divergence and large populations sizes/shallow divergences among species. BPP implements the reversible-jump Markov Chain Monte Carlo (rjMCMC) algorithm that moves between different species delimitation models. Since rjMCMC is known for exhibiting mixing problems in some datasets (Rannala and Yang, 2013), all the analyses were done several times to check if different starting tree models produced congruent results. We also analyzed the data using both algorithms ( 0 and 1$)$ to specify the rjMCMC moves (Table 1). Initially we used the automatic adjustment for the fine-tune variables for rjMCMC moves, but the results were always equal to the starting tree model indicating poor mixing. Thus, we used the manual adjustment for the fine-tune parameters on species delimitation algorithm 1, according to the program documentation. Even though we only got ideal fine-tune adjustments for algorithm 0 . All runs consisted of 50,000 samples taken every five steps with a burn-in period of 10,000 steps.

Table 1. Posterior probabilities $(p)$ in the different schemes tested for BPP analyses. $\varepsilon, \alpha$, and $m$ are different fine-tune parameters. $\vartheta$ and $\tau$ are the prior distribution schemes for ancestral population size and root age, respectively.

\begin{tabular}{|l|l|l|l|l|l|}
\hline Scheme & Algorithm & $\boldsymbol{\vartheta}$ & $\boldsymbol{\tau}$ & Description & Result \\
\hline 1 & $0(\varepsilon=5)$ & $G(2$, & $G(2$, \\
$2000)$ & $\begin{array}{l}\text { Small population } \\
\text { size } \\
\text { Shallow } \\
\text { divergence }\end{array}$ & $\begin{array}{l}\text { Favors the model that all five groups } \\
\text { belong to different species }(p=1.00)\end{array}$ \\
\hline 2 & $0(\varepsilon=5)$ & $G(1,10)$ & $G(1,10)$ & $\begin{array}{l}\text { Large population } \\
\text { size } \\
\text { Deep divergence }\end{array}$ & $\begin{array}{l}\text { Favors the model that all five groups } \\
\text { belong to different species }(p=1.00)\end{array}$ \\
\hline 3 & $0(\varepsilon=5)$ & $G(1,10)$ & $G(2$, & $\begin{array}{l}\text { Large population } \\
\text { size } \\
\text { Shallow } \\
\text { divergence }\end{array}$ & $\begin{array}{l}\text { Favors the model that all five groups } \\
\text { belong to different species }(p=1.00)\end{array}$ \\
\hline
\end{tabular}




\begin{tabular}{|l|l|l|l|l|l|}
\hline 4 & $1(\alpha=2, m=1)$ & $\begin{array}{l}G(2, \\
2000)\end{array}$ & $\begin{array}{l}G(2, \\
2000)\end{array}$ & $\begin{array}{l}\text { Small population } \\
\text { size } \\
\text { Shallow } \\
\text { divergence }\end{array}$ & Poor mixing \\
\hline 5 & $1(\alpha=2, m=1)$ & $G(1,10)$ & $G(1,10)$ & $\begin{array}{l}\text { Large population } \\
\text { size } \\
\text { Deep divergence }\end{array}$ & Poor mixing \\
\hline 6 & $1(\alpha=2, m=1)$ & $G(1,10)$ & $\begin{array}{l}G(2, \\
2000)\end{array}$ & $\begin{array}{l}\text { Large population } \\
\text { size } \\
\text { Shallow } \\
\text { divergence }\end{array}$ & Poor mixing \\
\hline
\end{tabular}

\subsection{Species distribution models and niche conservatism/divergence analyses}

To test our third hypothesis (which predicts that major diversification within N. meridionalis is due to allopatric speciation associated with niche conservatism), we performed a background similarity test between pairs of minimum convex polygons that circumscribe the sampling sites of the highly supported groups identified by gene trees and BAPS and validated with BPP using the R package phyloclim (Heibl and Calenge, 2011). The background similarity test asks whether environmental niche models of pairs of geographic areas are more different than expected by chance, by comparing a focal region to pseudoreplicate models generated by randomly subsampling the background of its paired region (Warren et al., 2008). We used Schoener's $D$ statistic for niche overlap and the similarity statistic / to quantify niche similarity; both statistics range from 0 (no overlap) to 1 (identical niche models). The species distribution models used by phyloclim were estimated with Maxent 3.3 (Phillips et al., 2010), using 122 independent occurrence localities, 25\% of random points for test, and 19 spatial bioclimatic variables (see Santos et al., 2014, Werneck et al., 2012d) from the WorldClim database with 30 arc-sec resolution (Hijmans et al., 2005).

We selected lineages 2 and 3 to perform the background similarity test, since these lineages included most of the sampled sites (lineages 1, 4, and 5 were sampled in either one or very few localities, rendering geographic variation analyses impossible).

\subsection{Non-stationary analyses, isolation-by-distance, and geographic barrier tests}

Since our third hypothesis also predicts that the inability of lineages to adapt to novel climatic conditions favors the appearance of geographic barriers to gene flow, we determined if genetic differentiation between individuals within genetic groups increased at different rates in different regions of the Brazilian Cerrado, i.e., a nonstationary pattern of isolation by distance consistent with a scenario of niche conservatism explaining the diversification. We used LocalDiff 1.5 (Duforet-Frebourg and Blum, 2014), which uses kriging, a method that can interpolate genetic distances in unsampled sites based on genetic distances measured at sampled sites. The interpolation is dependent on a weighted average of values measured at all sampling sites, and the weights rely on a parametric function that provides the decay of the similarity matrix with geographic distance. The similarity matrix was estimated as 1 - (genetic distance/maximum genetic distance); therefore, local genetic differentiation ranged from 0 (site with the lowest local differentiation) to 1 (site with the highest local differentiation). The maximum genetic distance corresponded to the largest genetic distance found within genetically divergent groups identified previously. The output of GenDiff generates a minimum convex polygon that encompasses all sampling sites within a genetic group, where warmer colors represent areas with stronger local genetic differentiation. 
Genetic distances between all mitochondrial ND2-alignment pairs were estimated assuming the K2P model in MEGA 4.0 (Tamura et al., 2011), using the pairwise-deletion option. In LocalDiff we implemented the following parameters: two fictional neighboring populations in the vicinity of each sampled site, and a geographic distance between the neighbors and the sampling sites of $0.1 \mathrm{~km}$. LocalDiff measures were averaged over 1000 replicates.

Because LocalDiff assumes isolation by distance (Duforet-Frebourg and Blum, 2014), we checked whether population differentiation indeed increased with increasing geographical distance by estimating the relationship between geographic and genetic distances with multiple matrix regression with randomization (MMRR) (Wang and Bradburd, 2014), which tests the significance of a simple or multiple regression using a randomized permutation procedure to account for the potential non-independence among samples. Geographic distances were estimated with Geographic Distance Matrix Generator (Ersts, 2011). We performed the MMRR method using the R function from lan Wang (Wang and Bradburd, 2014) with 10,000 permutations.

We determined the geographic position of potential barriers to gene flow between genetically divergent groups with Barrier 2.2 (Manni et al., 2004). This program generates a geometric network connecting all sampled haplotypes to identify boundaries where differences between pairs of haplotypes are largest, using Monmonier's maximum-difference algorithm on a genetic distance matrix (Manni et al., 2004). We estimated the robustness of each barrier by bootstrapping the DNA alignment (100 replicates) using seqboot and dnadist in the PHYLIP package (Felsenstein, 1989).

\section{Results}

\subsection{Gene tree, species tree, divergence times, and spatiotemporal phylogeography}

Our $\mathrm{BI}$ and $\mathrm{ML}$ concatenated gene tree inference methods recovered almost identical topologies (Figs. 2 and $\underline{\mathrm{S}}$ ). The ND2 individual gene agreed with the concatenated gene tree topology, while the individual nuclear genes showed some disagreement in the relationships among major clades compared with the concatenated tree (Fig. S1). For simplicity, we present here the Bayesian consensus phylogeny obtained from the concatenated analysis (Fig. 2). We found that the nominal species N. meridionalis comprises five highly divergent and well-supported lineages (Fig. 2). Samples within these lineages were collected at non-overlapping geographic distributions, with the notable exception of clades 3 and 4, which were sympatric and syntopic in extreme southwestern Goiás (Fig. 1). The most divergent lineage (lineage 5 ) corresponded to a single individual collected in northern Goiás, and it was the sister group to all other samples within N. meridionalis, having a mean ND2 sequence divergence between groups (number of base differences per site from averaging over all sequence pairs between groups) of $17 \%$ against all internal clades (see the percent sequence divergence for each nuclear gene in Table S3). The next well-defined group was lineage 4, sampled in Mato Grosso and Mato Grosso do Sul, which formed the sister group to the other three lineages and was separated from the remnant internal clades by a 16\% ND2 sequence divergence. Finally, lineage 3 (widely sampled in Goiás, Distrito Federal, and Minas Gerais) was the sister group of lineages 1 (sampled in Rondônia) and 2 (sampled in Mato Grosso, Piauí, Maranhão, and Tocantins), which were separated by a $7 \%$ mean sequence divergence. 


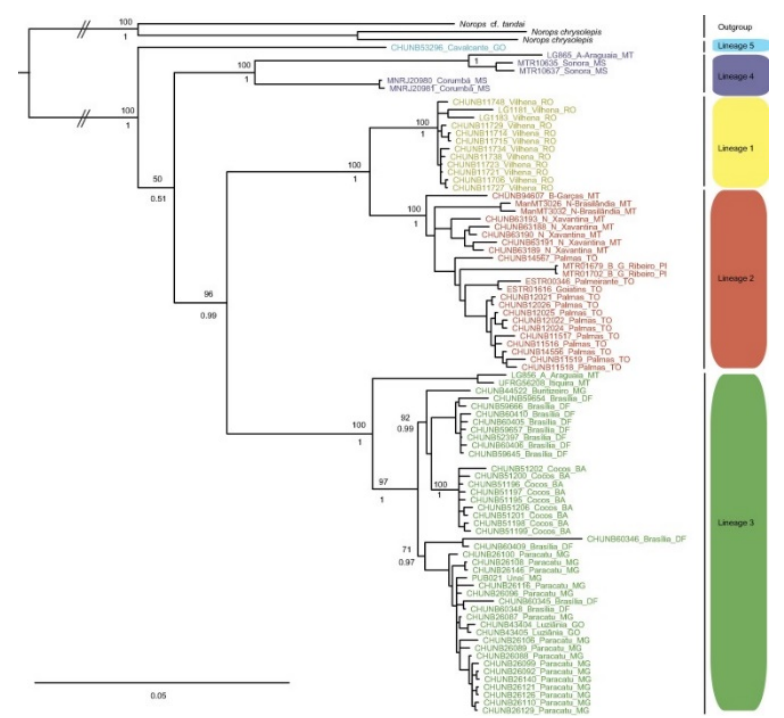

Fig. 2. Bayesian gene genealogy using the concatenated, partitioned dataset with four loci for Norops meridionalis. Statistical support for clades is indicated by maximum-likelihood bootstrap values (above each node) and Bayesian posterior probabilities (below each node). Each lineage depicted with the colored boxes is a group with a high statistical support in BAPS and BPP. Colors are the same depicted in the map of Fig. 1. (For interpretation of the references to color in this figure legend, the reader is referred to the web version of this article.)

The species tree recovered with high support most of the relationships found in the gene genealogies, except the sister clade relation between lineages $1+2$ and lineages $3+4$, which had low support (Fig. 3 ). Also, the species tree topology differed from the gene genealogy topology by having lineages 3 and 4 as sister groups (Fig. $\underline{3}$ ), while in the gene genealogy lineage 4 was the sister group to the clade consisting of lineages 1, 2, and 3 (Fig. 2). Lineage 5, from Cavalcante, Goiás, in central Brazil, diverged from all other $N$. meridionalis lineages about 21.6 mya (95\% highest posterior density - HPD interval: 29.87-14.83) during the Oligocene-Miocene transition. Although all crown lineages diverged in the Miocene, within-lineage diversification continued into the Pliocene and Pleistocene.

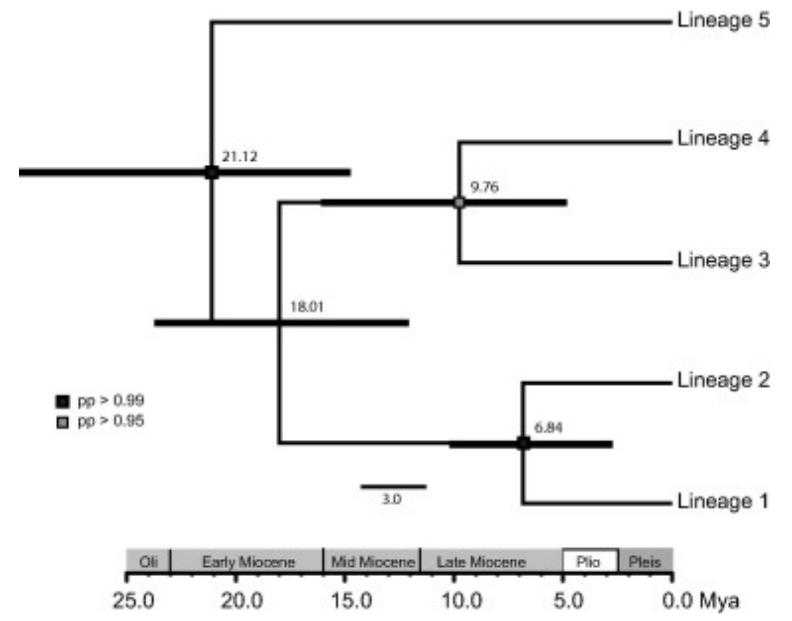

Fig. 3. Species tree estimation of Norops meridionalis lineages. Horizontal bars represent the $95 \%$ posterior credibility intervals of the divergence time estimates. Numbers under the gray box indicate estimated ages in millions of years ago (mya).

The Bayesian relaxed random walk model estimated the origin of $N$. meridionalis lineages to be located in western Goiás state at about 25.4 mya (95\% HPD: 34.8-16.5), with independent long distance 
lineage diffusion events to Mato Grosso, Mato Grosso do Sul, Rondônia, Tocantins, Piauí, and Bahia starting at about 10 mya (95\% HPD: 16.2-7.3) (Fig. 4). These diffusion events seem to include quite long distances, but can also represent geographic sampling gaps in the intervening regions. In other words, most of the deep divergence events within $N$. meridionalis ( $>10 \mathrm{my}$ ) appear to have occurred within the central part of the current distribution, while some diffusion events to Rondônia and Piauí occurred more recently ( $<5 \mathrm{my})$, during the final establishment of peripheral populations.

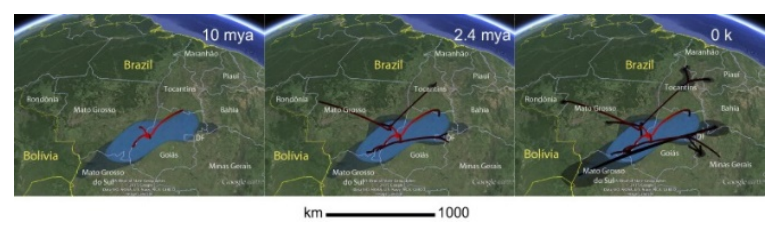

Fig. 4. Bayesian spatiotemporal model of Norops meridionalis at three time slices: 0, 2.4, and 10 million years ago (mya). Reconstructions are based on the maximum clade credibility tree estimated with a time-heterogeneous relaxed random walk approach. Shading represents $80 \%$ HPD uncertainty in the location of ancestral branches with lighter and darker shades representing older and younger diffusion events, respectively.

\subsection{Genetic clustering and species delimitation}

Using the concatenated dataset, BAPS revealed five highly supported genetic clusters (probability = 1; Fig. S2). Moreover, for all different prior distributions used, the BPP method consistently found very high speciation probabilities (1.0) for all internal nodes. In other words, according to our BPP analysis, all five groups identified in BAPS have high probability of representing different species (Table 1).

\subsection{Niche conservatism/divergence}

The background similarity test using the species distribution model revealed a statistically significant similarity of abiotic niches between lineage 3 and the background of lineage 2, with values of Schoener's $D$ and the similarity statistic / significantly higher than the null distributions obtained from 100 randomizations $(P<0.01$; Fig. S3 and

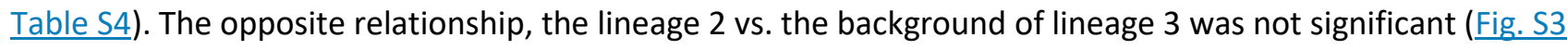
and Table S4). These results suggest that the climatic niches of lineages 2 and 3 have not differentiated significantly, supporting the role of niche conservatism at small geographic scales, since these two lineages were sampled parapatrically to each other.

\subsection{Non-stationary analyses, isolation-by-distance, and geographic barrier tests}

We found evidence for isolation by distance within lineages 2 and 3 , with significant associations between geographic and genetic distances (lineage 2: $r^{2}=0.494, P<0.001$; lineage $3: r^{2}=0.396, P<0.001$ ). Both lineages displayed a steep gradient in the local genetic differentiation across geography ( $\underline{\text { Fig. } 5}$ ); however, local genetic differentiation was higher in both west and east ends of the minimum convex polygon that circumscribes lineage 2, in the municipalities of Nova Brasilândia (map code 8) and Baixa Grande do Ribeiro (map code 3), respectively. In lineage 3, local genetic differentiation was larger in Itiquira (map code 19), which lies in the western end of lineage 3 distribution (Fig. 5). In summary, genetic differentiation between localities was not homogeneous across space within each lineage, instead it was higher at the west and/or east extremes of their distributions.

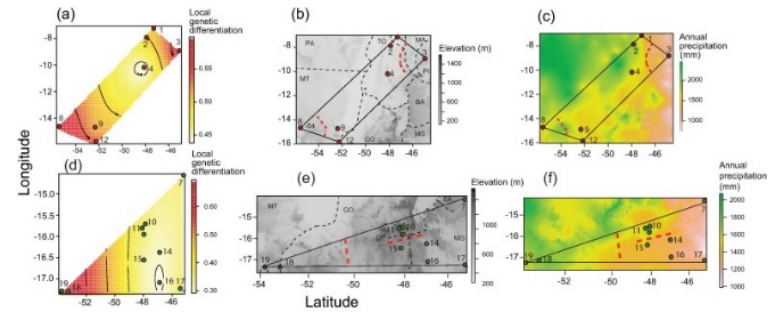


Fig. 5. Comparison between local genetic differentiation and characteristics of topography and precipitation within two cryptic lineages found in Norops meridionalis - lineage 2 (top) and lineage 3 (bottom); (a and d) Local genetic differentiation within $N$. meridionalis in lineage 2 (top) and lineage 3 (bottom). Shapes represent the minimum convex polygon that encompasses the sampling sites of each lineage. Numbers correspond to sampling localities depicted in Fig. 1 and Table S1. Warmer colors indicate higher local genetic differentiation (higher genetic distances between individuals at sampled sites and interpolated unsampled neighbors). Local genetic differentiation was estimated using a normalized similarity matrix, and it measures 1 - (genetic distance between sampled individuals and unsampled neighbors divided by maximum genetic distance within the nominal species), at a resolution of $0.1 \mathrm{~km}$; (b and e) Topographic map showing elevation above sea level. The polygons and numbers correspond to the same region on the left. Red dotted lines indicate high supported (100\% bootstrap) genetic discontinuities identified by Barrier 2.2; ( $\mathrm{c}$ and f) Mean annual precipitation (averaged over the last 50 years) obtained from the WorldClim dataset. The polygon represents the same geographic area depicted in the first two columns. Black dotted lines in the two central panels delineate Brazilian states borders. (For interpretation of the references to color in this figure legend, the reader is referred to the web version of this article.)

Finally, Barrier analysis within each lineage found two significant genetic discontinuities in lineage 2 (bootstrap 100\%; Fig. 5), separating from the central region samples from Nova Brasilândia (map code 8) at the western extreme and Baixa Grande do Ribeiro (map code 3) at the eastern extreme (Fig. 5). In lineage 3, Barrier found three highly supported genetic discontinuities, one in the extreme west end of the minimum convex polygon near São Vicente (Mato Grosso), one in the central region near Santa Helena de Goiás (Goiás), and a third one near Brasília (Distrito Federal).

\section{Discussion}

\subsection{Cryptic diversity within Norops meridionalis}

The nominal species Norops meridionalis, as currently known (see distribution model in Fig. 1a), is supposed to have a wide geographic distribution in the Cerrado of Brazil, Paraguay, and Bolivia (Langstroth, 2006). Our genetic results, however, contradict this perspective indicating that rather than a single species $N$. meridionalis is composed by at least five geographically restricted cryptic species separated by deep genetic divergences. These five lineages were consistently supported by two independent analyses that take into account factors such as uncertainties due to unknown gene trees and the ancestral coalescent process (Yang and Rannala, 2010). Moreover, the fact that two of the lineages encountered (lineages 3 and 4) occur

sympatrically and syntopically ( $\underline{\text { Fig. } 1)}$ reinforces the hypothesis that these are different species, since the strong genetic divergence observed is maintained despite the close geographic proximity between sampled individuals.

The genetic divergence found between $N$. meridionalis lineages is much higher than the genetic divergence found in other anoles with comparable geographic distributions. For instance, the widely distributed species $N$. fuscoauratus from the Amazon rainforest shows a general lack of phylogeographic structure and low (3-4\%) interpopulational divergence (Glor et al., 2001). Other widely distributed species, however, display stronger genetic structures. For example, the four genetic groups found in Anolis carolinensis (Tollis et al., 2012) from southeastern North America are separated by a maximum ND2 mean sequence divergence (with a Tamura-Nei correction) of $7.5 \%$ (Tollis et al., 2012). The two most divergent lineages within $N$. meridionalis, however, are separated by a ND2 sequence divergence (using the same correction) of $22 \%$, which is three times as high as the divergence within A. carolinensis. Similarly, the sequence divergence found among $N$. meridionalis lineages is higher than the ND2 $p$-distance that separates various species pairs such as N. sagrei and N. isthmicus: $\sim 11 \%$ (Nicholson et al., 2005), N. onca and N. annectens: $\sim 13 \%$ (Nicholson et al., 2006), and even within the $N$. chrysolepis group, as in N. scypheus and N. bombiceps: 11\% (D’Angiolella et al., 2011).

For all the reasons mentioned in the above paragraphs, including the evidence from species delimitation methods (see below) we conclude that $N$. meridionalis is a complex composed of at least five cryptic species. 
Since we do not have samples from the $N$. meridionalis type and neotype localities in Paraguay (Motte and Cacciali, 2009), it is possible that none of the five lineages found here corresponds to N. meridionalis sensu stricto. Furthermore, because we focus on the patterns and processes promoting diversification in $N$. meridionalis, formal descriptions of the cryptic species discovered here are beyond the goals of our study.

\subsection{Divergence among cryptic lineages}

Classical studies on the historical biogeography of beta anoles have suggested that Norops originated in MexicoCentral America, and only recently (after the Pliocene) invaded South America as a result of the closure of the Panamá gap (Vanzolini and Williams, 1970, Williams, 1969), which early estimates indicate to have occurred $\sim 3.5$ mya. The same authors also indicate that $N$. meridionalis would be a surviving representative of the first wave of beta anole invasion of South America (Vanzolini and Williams, 1970). Our results, however, indicate older divergence times within the nominal $N$. meridionalis that do not agree with a Pliocene invasion of South America, but with an early-mid Miocene invasion. Other studies support this same perspective, showing deep divergences among Norops clades, and suggesting that South America was colonized earlier by Norops, way before the Pliocene (Nicholson et al., 2005). In agreement, two recent studies conclude that the Panama gap actually closed way before the Pliocene, around 13-15 mya (Bacon et al., 2015, Montes et al., 2015), which falls into our $95 \%$ credible interval of our older divergence time estimation. This older connection between North and South America would allow for an earlier invasion of Norops across South America, potentially explaining the deep divergences found within South American beta anoles.

The deep divergence found within N. meridionalis supports our first hypothesis, that at broader temporal and geographical scales the genetic divergence in $N$. meridionalis is mainly explained by old, rather than young events. Simultaneously, we rejected our second hypothesis, finding that the deepest branches split back into the early-mid Miocene, when most of the geophysical activity of the Cerrado took place (Mulch et al., 2010, Uba et al., 2006). We found some noticeable differentiation in the elevation range between the two lineages with better geographical sampling. For instance, lineage 2 appears to have a lower elevation range (159-630 masl), compared with lineages 3 and 4 (602-1221 masl). Even though this elevation segregation could be an artifact of limited sampling within these two lineages, it is possible that these disparate elevation ranges are a relict of a past where allopatric reproductive isolation was promoted by tectonic and paleogeographic reorganizations, such as the uplift of the Central Brazilian Plateau (Machado et al., 2014). In other words, it is possible that an ancestral N. meridionalis lineage was distributed over the central Cerrado landscape before the topographic reorganization during the Miocene and, then, habitat stratification might have isolated plateaus and depressions promoting geographic isolation, as suggested for other Cerrado vertebrates (Domingos et al., 2014, Giugliano et al., 2013, Prado et al., 2012). Even though the timing of the first divergence event of $N$. meridionalis also agrees with the time when the Atlantic ocean transgressed up southern Bolivia through the Paraná basin (Lundberg et

al., 1998), this marine transgression was too far from central Goiás (where most divergent lineages within $N$. meridionalis are found) to have split by vicariance the lineages found in this study. Certainly, however, additional samples of the nominal N. meridionalis from Paraguay and Bolivia might change this conclusion. Therefore, we hypothesize that the main process that explains the observed genetic pattern in $N$. meridionalis is geographic isolation due to paleogeographic reorganizations in central Cerrado, rather than vicariance due to the Paraná basin marine transgressions.

Our Bayesian relaxed random walk model estimated the spatiotemporal dynamics of lineages within $N$. meridionalis, placing its geographic origin (with a 80\% HPD) between the states of Goiás and Mato Grosso around 25 mya. This scenario suggests that the distribution of early lineages might have been restricted to the central Cerrado area. After a long period of geographic stasis, major divergence events ( 10 mya) might have occurred within the central Cerrado before the occurrence of diffusion events that agree with the spatial patterns of genetic diversity found (Fig. 5 ). In other words, the major divergence events might have occurred as 
a consequence of geomorphological rearrangements in central Cerrado combined with subsequent longdistance migrations, followed by geographic diffusion and further diversification. The final establishment of the peripheral populations of these lineages took place in the last $2.5 \mathrm{my}$. Therefore, we believe that a combination of vicariance at the deeper levels and dispersal at the shallower levels were important for the genetic diversification of the meridionalis complex.

The pattern of diversification within N. meridionalis follows a northwest-southeast directionality (Fig. 1), having in the northwestern extreme lineage 1 in the state of Rondônia, and lineage 3 at the southeastern extreme in Goiás and Minas Gerais. This northwest-southeast differentiation has been observed in other endemic Cerrado vertebrates, such as the frog Hypsiboas albopunctatus (Prado et al., 2012) and the lizard Micrablepharus atticolus (Santos et al., 2014). This pattern, however, is not ubiquitous. For example, the gecko Phyllopezus pollicaris shows a southwest-northeast pattern instead (Werneck et al., 2012a), a pattern shared by other savanna lizard endemics such as Vanzosaura spp. (Recoder et al., 2014), and Micrablepharus maximiliani (Werneck, Pers. Commu.).

We believe these two contrasting and prevalent geographical patterns are dependent on two main factors: (a) how large the range of the lineage is, and (b) whether the lineage is endemic to the Cerrado or not. We find, for instance, that the species that are not endemic to the Cerrado and whose ranges span the whole South American dry diagonal display a southwest-northeast pattern likely resultant from the effect of the altitudinal break caused by the uplift of Central Brazilian Plateau on the fragmentation of populations (Nogueira et al., 2011, Werneck, 2011). On the contrary, Cerrado-endemic species (such as N. meridionalis) display striking similarities in their southeast-northwest genetic differentiation pattern likely resulting from geomorphological features aligned perpendicularly to the southwest-northeast axis across the Cerrado.

The diversification of the Cerrado endemic lizards, therefore, is consistent across species and appears to be driven by geomorphological processes fragmenting populations during the early-mid Miocene. Alternative factors explaining the diversification patterns across Cerrado-endemic species, such as migrations into and from the Amazon and Atlantic Forest, climatic stability, as well as idiosyncratic factors dependent on the natural history of each species, seem to have less explanatory power relative to geomorphology and time.

\subsection{Variation within cryptic lineages}

In the presence of isolation by distance alone, the rate at which individuals differentiate should not be affected by the landscape (Duforet-Frebourg and Blum, 2014). We found evidence, however, of non-stationary isolation by distance within lineages 2 and 3, the lineages with better geographic sampling (Fig. 5). In other words, the rate at which individuals differentiate within these two lineages depends on the landscape. For instance, within lineage 2 there was higher local genetic differentiation (warmer colors) near the extreme west and east ends of the lineage 2-distribution (near Chapada dos Guimarães, in Mato Grosso, and Serra do Penitente, in Maranhão, respectively). These two regions are characterized by mid-elevations ( 600 masl) and complex topographies. Meanwhile, the lower local genetic differentiation (colder colors) in lineage 2 is placed along the intervening flat Araguaia-Tocantins basin, characterized by lower elevations ( 180 masl) and relatively high annual precipitation values (above $2000 \mathrm{~mm}$ ) ( $\underline{\mathrm{Fig} .5}$ ). Our Barrier analysis confirmed these results placing two statistically supported genetic discontinuities isolating the two most western and eastern-end populations (Fig. 5), suggesting that while the flat topographic conditions of the Araguaia-Tocantins may promote gene flow among populations, the complex topographies of the extreme-end regions are likely acting as geographic barriers to gene flow, promoting lineage 2 extreme-ends genetic divergence. Also, we noticed that the presence of geographic barriers was more closely associated with topographic variables than with precipitation variables.

We found a similar pattern in lineage 3 , with the highest local genetic differentiation near the Planalto do Alto Tocantins-Paranaíba, a region surrounded by Serra da Estrela, a ridge that reaches $700 \mathrm{~m}$, while the region with 
lowest local genetic differentiation is near Paracatu (Minas Gerais), a topographically homogeneous region. The two supported barriers within lineage 3 also support the role of topographic features as geographic barriers, having a nice agreement between the geographic position of the genetic discontinuities and the topographic, as well as the precipitation profile of the landscape (Fig. 5 ).

The results in both lineages suggest that genetic differentiation is higher in regions with more complex topographies, presumably as a result of topography preventing high gene flow among populations, while the regions with flatter topographies might promote higher gene flow, decreasing the overall differentiation across small geographic scales. We noticed, however, that the geographic regions with more complex topographies were not necessarily the ones with higher local genetic differentiation, as can be seen in Fig. 5 . Clearly, besides topography, local genetic differentiation may be affected by precipitation, as well as a multitude of demographic and historical biogeographic processes that we did not measured in this study (Avise, 2000, Barton and Wilson, 1995, Wade and McCauley, 1988). It is clear, however, that topography plays an important role promoting intra and interspecific genetic divergence.

In summary, we found that LocalDiff and Barriers provided complementary information on the factors that might be influencing the genetic patterns observed. For N. meridionalis, we nominate the Araguaia-Tocantins basin, the Chapada dos Guimarães, Serra do Penitente, Planalto do Alto Tocantins-Paranaíba, and Serra da Estrela as the main geomorphological features promoting intraspecific genetic divergence at least in lineages 2 and 3.

\subsection{Niche conservatism vs. niche divergence}

Anoles are a classical example of evolutionary divergence frequently overcoming niche conservatism (Knouft et al., 2006, Losos, 2008). Several examples of Anolis lizards have shown a persistent ability to diversify in ecomorphs and microhabitat preferences once they encounter novel habitats such as the Caribbean Islands (Losos et al., 2003). We did not measure the niche in terms of ecomorphs or microhabitat preferences, and therefore we cannot conclude if niche divergence or conservatism (at a fine-grain level) is supported in $N$. meridionalis. From a climatic perspective, however, our background similarity test fails to find evidence that the climatic niches between lineages 2 and 3 are more different than expected by chance. In other words, using a species distribution model approach, our data supports niche conservatism, rather than niche divergence, as the main process leading to the diversification of these two lineages. If this assumption is correct, then the mechanistic explanation for the diversification within $N$. meridionalis may be related with the inability of populations to adapt fast to novel climatic conditions. In other words, due to either stabilizing selection, gene flow, genetic constraints due to pleiotropy, and/or lack of appropriate genetic variation (Wiens and Graham, 2005), populations of the ancestral N. meridionalis were not able to adapt to novel conditions provided by the uplifted Brazilian Plateau during the early-mid Miocene, promoting the appearance of geographic barriers to gene flow. In fact, there is research that suggests lizards exhibit a conservative thermal physiology and rely on behavioral thermoregulation to face cold and variable temperatures (Navas, 2002), which supports the role of niche conservatism at least in some species.

We cannot, however, rule out niche divergence as the predominant mechanism that promoted diversification within N. meridionalis, mainly because (a) we only tested two out of five lineages for climatic niche similarity, (b) we did not include fine grain ecogeographic variables, and (c) we admittedly used coarse bioclimatic variables to describe the climatic niche (which might explain the fact that the background similarity test was unable to detect significant differences in the climatic niches between lineages 2 and 3, even though their sampled localities are noticeable different in terms of their elevation range). Since some studies have found that Anolis thermal biology can diverge really fast even between recently diverged taxa (Hertz et al., 2013), it is necessary to explore in more detail how prevalent are these two mechanisms in these Cerrado lizards. 


\section{Conclusions}

The Cerrado region was once considered a species-poor biome inhabited by generalist species (Vanzolini, 1976). However, our finding that $N$. meridionalis is not a single species, but a complex of five cryptic species instead agrees with the conclusions of recent studies that suggest the Cerrado is a tremendously diverse biome with a high proportion of endemic species (Gamble et al., 2012, Nogueira et al., 2010). The deep divergence times found in N. meridionalis suggest that beta anoles invaded South America earlier than previously thought. Even though the topographic heterogeneity of the Cerrado is not as conspicuous as other biodiversity hotspots such as the Northern Andes, it is clear that the complex topographic reorganization during the Miocene was an important factor in promoting genetic divergence both at inter and intraspecific scales in the Cerrado region. Although our data supports the role of niche conservatism as the main mechanism promoting allopatric speciation in the meridionalis complex, we only tested for it in two out of five lineages recovered here, and therefore we consider it as a preliminary result. We cannot rule out, therefore, the role of niche divergence and the effect of local ecological factors promoting diversification in N. meridionalis. We predict that cryptic species are prevalent and widespread in the Cerrado region. Finding and characterizing such species in the near future may change our current perspectives on the general processes that promote diversification in the open areas in South America, having significant conservation implications in the region.

\section{Acknowledgments}

CEG thanks Conselho Nacional do Desenvolvimento Científico e Tecnológico - CNPq (postdoctoral fellowship PDJ, 150104/2014-6) for funding. FPW thanks CNPq (Science Without Borders Program BJT-374307/2012-1 and Universal 475559/2013-4) and Fundação de Apoio à Pesquisa do Estado do Amazonas - FAPEAM (062.00665/2015) for funding. CS thanks CNPq for a research fellowship (process 309541/2012-3). TG was supported by NSF (IOS1146820). MTR thanks Fundação de Apoio à Pesquisa do Estado de São Paulo - FAPESP and CNPq for funding and D. Pavan, F. Curcio, N. Silva, and the late G. Skuk for help in field. GRC thanks Coordenação de Aperfeiçoamento de Pessoal de Nível Superior - CAPES, CNPq, and Fundação de Apoio à Pesquisa do Distrito Federal - FAPDF for funding. We thank P. Lemey for his help troubleshooting the final visual representation of the lineages diffusion and two anonymous reviewers for providing insightful comments that improved this manuscript. 


\section{Appendix A. Supplementary material}

Supplementary data 1.

1. Maximum likelihood (ML) gene tree for Norops meridionalis in the Brazilian Cerrado using the concatenated genes (ND2, NKTR, NGFB, and PRL). Statistical support for clades is indicated by bootstrap values on top of each node. Codes correspond to museum numbers depicted in Table 1.

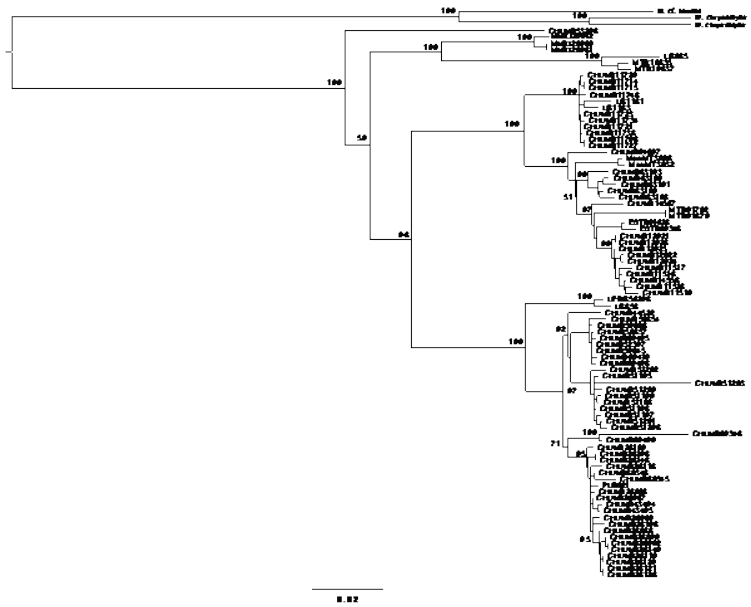

2. Bayesian ND2 gene tree for Norops meridionalis in the Brazilian Cerrado including as outgroups the species within the chrysolepis group. Statistical support for clades is indicated by posterior probabilities on top of each node. Codes correspond to museum numbers depicted in Table 1.

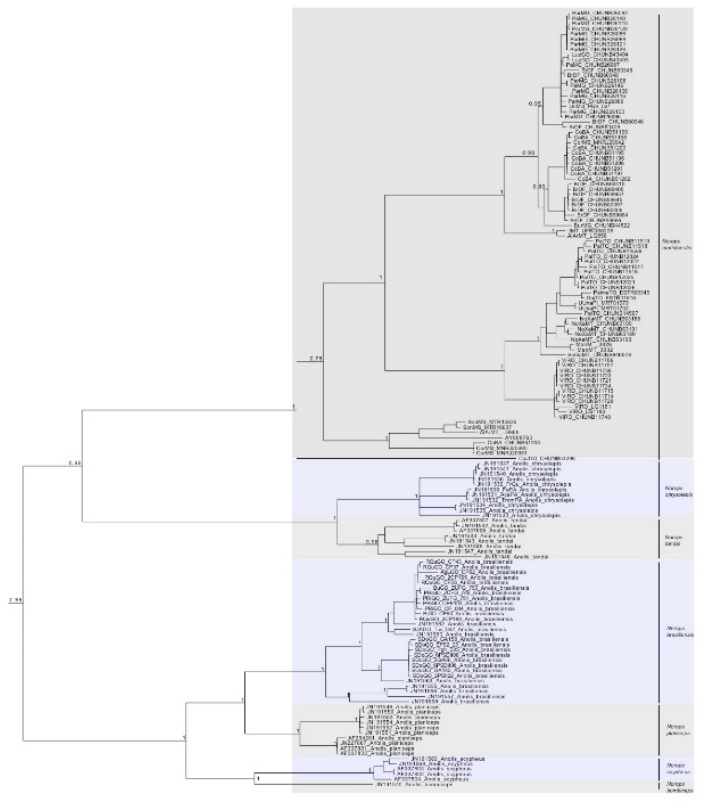


3. Bayesian ND2 gene tree for Norops meridionalis in the Brazilian Cerrado. Statistical support for clades is indicated by posterior probabilities on top of each node. Codes correspond to museum numbers depicted in Table 1.

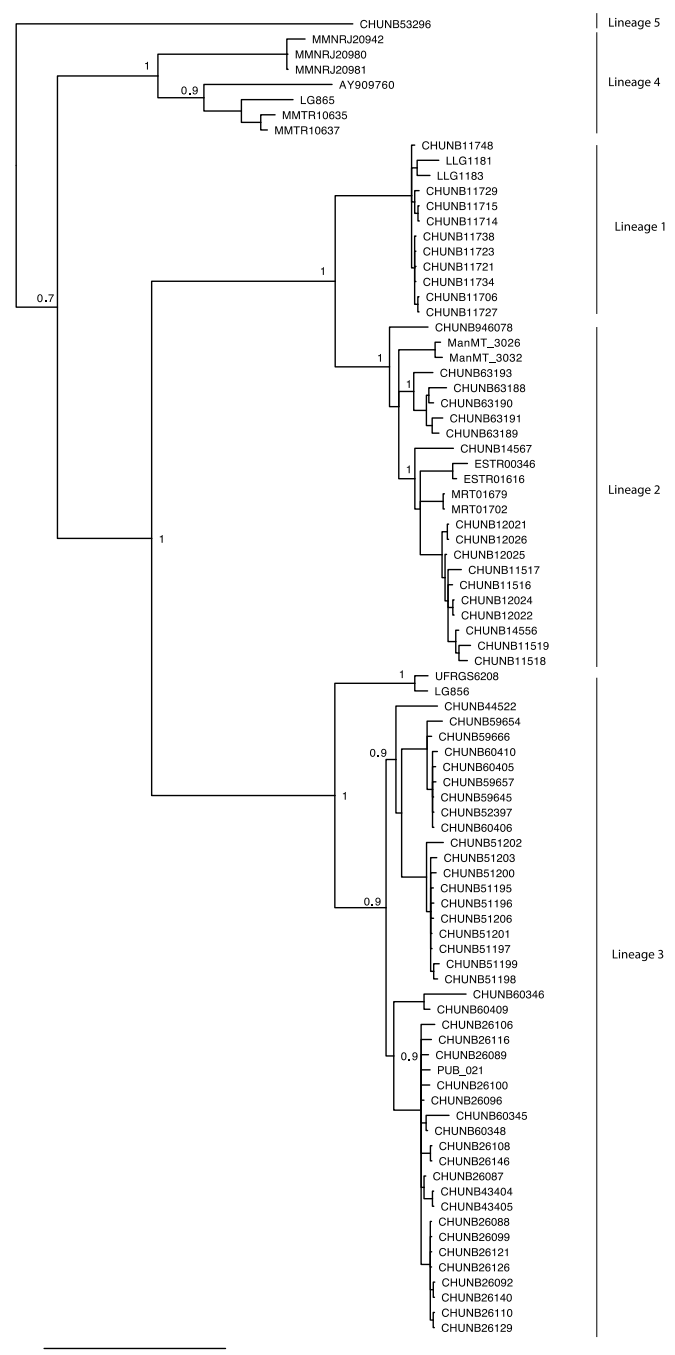

4. Bayesian NGFB gene tree for Norops meridionalis in the Brazilian Cerrado. Statistical support for clades is indicated by bootstrap values on top of each node. Codes correspond to museum numbers depicted in Table 1.

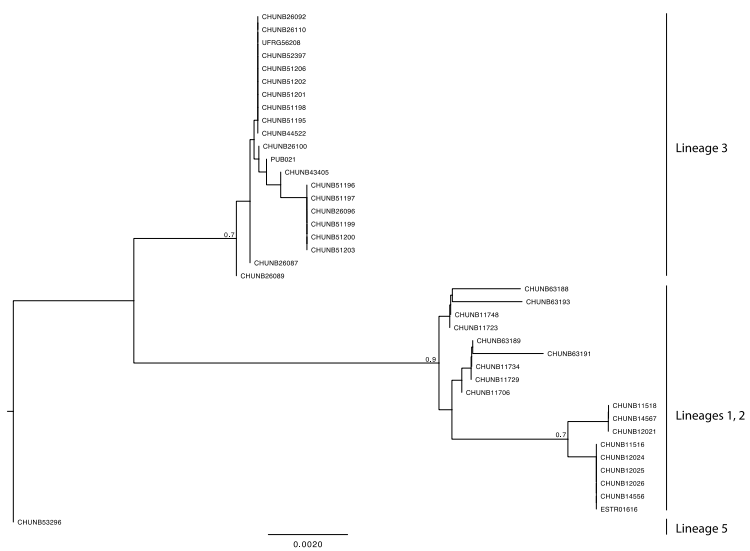


5. Bayesian NKTR gene tree for Norops meridionalis in the Brazilian Cerrado. Statistical support for clades is indicated by bootstrap values on top of each node. Codes correspond to museum numbers depicted in Table 1.

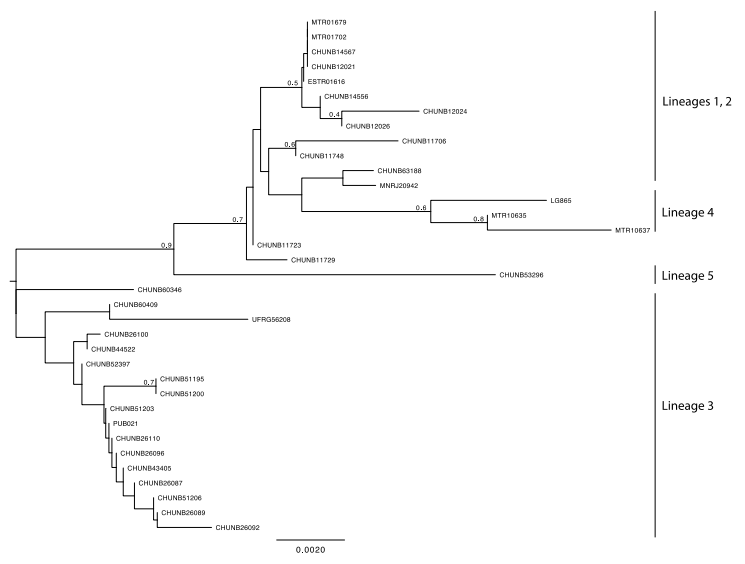

6. Bayesian PRL gene tree for Norops meridionalis in the Brazilian Cerrado. Statistical support for clades is indicated by posterior probabilities on top of each node. Codes correspond to museum numbers depicted in Table 1.

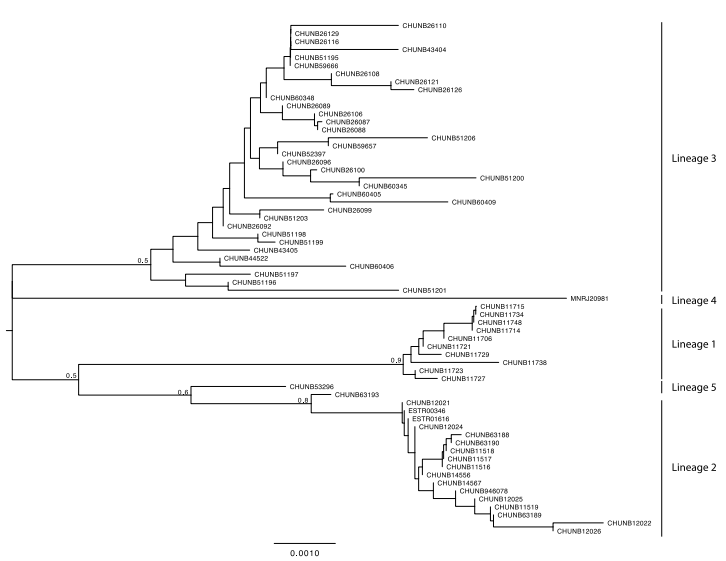


Figure S2. Genetic clusters defined by BAPS using the concatenated alignment (ND2, NGFB, NKTR, PRL). Each column corresponds to a different individual. This figure shows that Norops meridionalis divides into five genetically differentiated groups (depicted by different colors). When each individual show different colors, each color corresponds to one of the groups and this is evidence for admixture (which as observed, is very little).

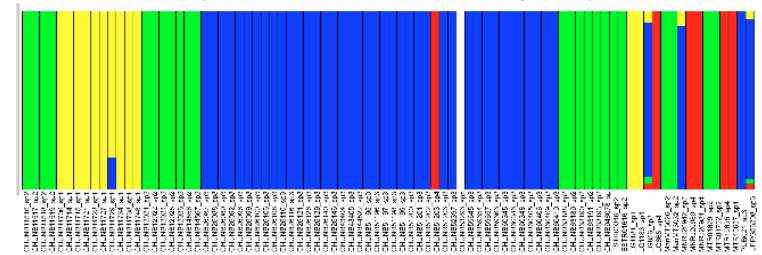

Figure S3. Background similarity test. Within each histogram, vertical red lines represent observed values in the background similarity tests calculated using PHYLOCLIM. Histograms (grey bars) show niche overlap values obtained from randomly sampling sites within the corresponding range. Values of Schoener's D (left column) and Similarity statistic I (right column) are shown on the x-axes. The different pairwise comparisons are: (top) Lineage 3 vs. Background of lineage 2, and (bottom) lineage 2 vs. background of lineage 3 .
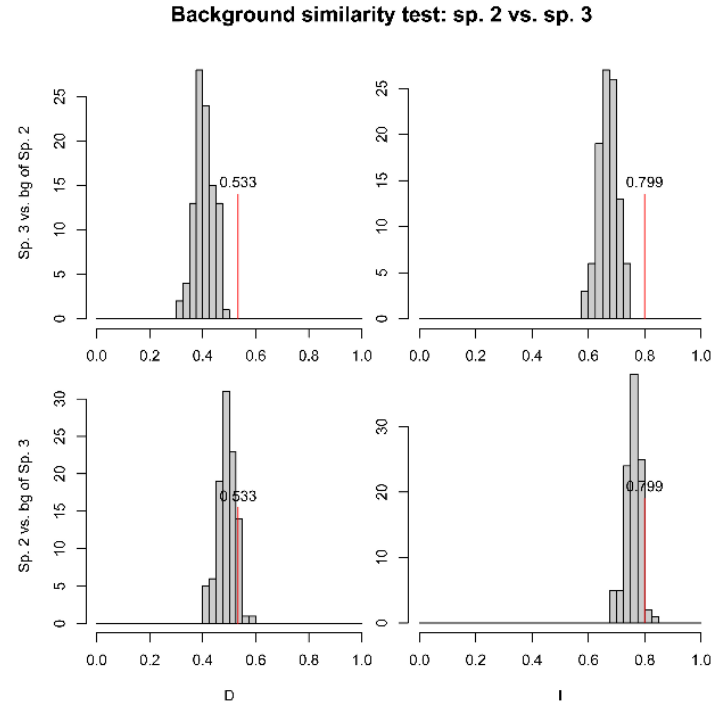
Table S1. Museum numbers, candidate species identifier (see text), map code, and GenBank accession numbers for each gene. CHUNB = Coleção Herpetológica da Universidade de Brasília; MTR = Miguel Treffaut Rodrigues field series deposited at Coleção de Tecidos de Vertebrados do Departamento de Zoologia, Instituto de Biociências, Universidade de São Paulo; MNRJ = Museu Nacional do Rio de Janeiro; UFG = Universidade Federal de Goiás; UFRGS = Universidade Federal do Rio Grande do Sul. Samples are organized from North to South.

\begin{tabular}{|c|c|c|c|c|c|c|c|c|}
\hline Museum number & \begin{tabular}{|l} 
Lineage \\
(candidate \\
species)
\end{tabular} & Locality (state) & \begin{tabular}{|l|} 
Geographic \\
Coordinates (Lat \\
$\mathrm{N}$, Long W)
\end{tabular} & $\begin{array}{l}\text { Map } \\
\text { code }\end{array}$ & $\begin{array}{l}\text { ND2 } \\
\text { GenBank } \\
\text { accession } \\
\text { number }\end{array}$ & \begin{tabular}{|l|} 
NKTR \\
GenBank \\
accession \\
number
\end{tabular} & $\begin{array}{l}\text { NGFB } \\
\text { GenBank } \\
\text { accession } \\
\text { number }\end{array}$ & \begin{tabular}{|l|} 
PRL \\
GenBank \\
accession \\
number
\end{tabular} \\
\hline MTR(ESTR01616) & 2 & Goiatins (TO) & $-7.1000,-47.3142$ & 1 & KT310780 & KT310817 & KT310860 & KT310919 \\
\hline MTR(ESTR00346) & 2 & Palmeirante (TO) & $-7.8600,-47.9258$ & 2 & - & - & - & KT310918 \\
\hline MTR01679 & 2 & Baixa Grande do Ribeiro (PI) & $-8.8803,-44.9706$ & 3 & KT310789 & KT310820 & - & - \\
\hline MTR01702 & 2 & Baixa Grande do Ribeiro (PI) & $-8.8803,-44.9706$ & 3 & KT310790 & KT310821 & - & - \\
\hline CHUNB11516 & 2 & Palmas (TO) & $-10.1891,-48.1085$ & 4 & KT310715 & - & KT310825 & KT310863 \\
\hline CHUNB11517 & 2 & Palmas (TO) & $-10.1891,-48.1085$ & 4 & KT310716 & - & - & KT310864 \\
\hline CHUNB11518 & 2 & Palmas (TO) & $-10.1891,-48.1085$ & 4 & KT310717 & - & KT310826 & KT310865 \\
\hline CHUNB11519 & 2 & Palmas (TO) & $-10.1891,-48.1085$ & 4 & - & - & - & KT310866 \\
\hline CHUNB12021 & 2 & Palmas (TO) & $-10.1891,-48.1085$ & 4 & KT310727 & KT310798 & KT310832 & KT310877 \\
\hline CHUNB12022 & 2 & Palmas (TO) & $-10.1891,-48.1085$ & 4 & KT310728 & - & - & KT310878 \\
\hline CHUNB12024 & 2 & Palmas (TO) & $-10.1891,-48.1085$ & 4 & KT310729 & KT310799 & KT310833 & KT310879 \\
\hline CHUNB12025 & 2 & Palmas (TO) & $-10.1891,-48.1085$ & 4 & KT310730 & - & KT310834 & KT310880 \\
\hline CHUNB12026 & 2 & Palmas (TO) & $-10.1891,-48.1085$ & 4 & KT310731 & KT310800 & KT310835 & - \\
\hline CHUNB14556 & 2 & Palmas (TO) & $-10.1891,-48.1085$ & 4 & KT310732 & KT310801 & KT310836 & KT310881 \\
\hline CHUNB14567 & 2 & Palmas (TO) & $-10.1891,-48.1085$ & 4 & KT310733 & KT310802 & KT310837 & KT310882 \\
\hline CHUNB11706 & 1 & Vilhena (RO) & $-12.1239,-60.2917$ & 5 & KT310718 & - & KT310827 & KT310867 \\
\hline CHUNB11714 & 1 & Vilhena (RO) & $-12.1239,-60.2917$ & 5 & KT310719 & - & - & KT310868 \\
\hline CHUNB11715 & 1 & Vilhena (RO) & $-12.1239,-60.2917$ & 5 & KT310720 & - & - & KT310869 \\
\hline CHUNB11721 & 1 & Vilhena (RO) & $-12.1239,-60.2917$ & 5 & KT310721 & - & - & KT310870 \\
\hline CHUNB11723 & 1 & Vilhena (RO) & $-12.1239,-60.2917$ & 5 & KT310722 & KT310795 & KT310828 & KT310871 \\
\hline CHUNB11727 & 1 & Vilhena (RO) & $-12.1239,-60.2917$ & 5 & KT310723 & - & - & KT310872 \\
\hline CHUNB11729 & 1 & Vilhena (RO) & $-12.1239,-60.2917$ & 5 & - & KT310796 & KT310829 & KT310873 \\
\hline CHUNB11734 & 1 & Vilhena (RO) & $-12.1239,-60.2917$ & 5 & KT310724 & - & KT310830 & KT310874 \\
\hline CHUNB11738 & 1 & Vilhena (RO) & $-12.1239,-60.2917$ & 5 & KT310725 & - & - & KT310875 \\
\hline
\end{tabular}




\begin{tabular}{|c|c|c|c|c|c|c|c|c|}
\hline CHUNB11748 & 1 & Vilhena (RO) & $-12.1239,-60.2917$ & 5 & KT310726 & KT310797 & KT310831 & KT310876 \\
\hline MTR(LG1181) & 1 & Vilhena (RO) & $-12.1239,-60.2917$ & 5 & KT310781 & - & - & - \\
\hline MTR(LG1183) & 1 & Vilhena (RO) & $-12.1239,-60.2917$ & 5 & KT310782 & KT310815 & - & - \\
\hline CHUNB53296 & 5 & Cavalcante (GO) & $-13.6424,-47.7217$ & 6 & KT310763 & - & - & KT310907 \\
\hline CHUNB51195 & 3 & $\operatorname{Cocos}(\mathrm{BA})$ & $-14.5451,-45.2421$ & 7 & KT310753 & KT310810 & KT310846 & KT310898 \\
\hline CHUNB51196 & 3 & $\operatorname{Cocos}(\mathrm{BA})$ & $-14.5451,-45.2421$ & 7 & KT310754 & - & KT310847 & KT310899 \\
\hline CHUNB51197 & 3 & $\operatorname{Cocos}(\mathrm{BA})$ & $-14.5451,-45.2421$ & 7 & KT310755 & - & KT310848 & KT310900 \\
\hline CHUNB51198 & 3 & $\operatorname{Cocos}(\mathrm{BA})$ & $-14.5451,-45.2421$ & 7 & KT310756 & - & KT310849 & KT310901 \\
\hline CHUNB51199 & 3 & $\operatorname{Cocos}(\mathrm{BA})$ & $-14.5451,-45.2421$ & 7 & KT310757 & - & KT310850 & KT310902 \\
\hline CHUNB51200 & 3 & $\operatorname{Cocos}(\mathrm{BA})$ & $-14.5451,-45.2421$ & 7 & KT310758 & KT310811 & KT310851 & KT310903 \\
\hline CHUNB51201 & 3 & $\operatorname{Cocos}(\mathrm{BA})$ & $-14.5451,-45.2421$ & 7 & KT310759 & - & KT310852 & KT310904 \\
\hline CHUNB51202 & 3 & $\operatorname{Cocos}(\mathrm{BA})$ & $-14.5451,-45.2421$ & 7 & KT310760 & - & KT310853 & - \\
\hline CHUNB51206 & 3 & $\operatorname{Cocos}(\mathrm{BA})$ & $-14.5451,-45.2421$ & 7 & KT310761 & KT310813 & KT310855 & KT310906 \\
\hline MTR(ManMT3026) & 2 & Nova Brasilândia (MT) & $-14.6667,-55.5833$ & 8 & KT310785 & - & - & - \\
\hline MTR(ManMT3032) & 2 & Nova Brasilândia (MT) & $-14.6667,-55.5833$ & 8 & KT310786 & - & - & - \\
\hline CHUNB63188 & 2 & Nova Xavantina (MT) & $-14.6733,-52.3531$ & 9 & KT310773 & - & KT310857 & KT310913 \\
\hline CHUNB63189 & 2 & Nova Xavantina (MT) & $-14.6733,-52.3531$ & 9 & KT310774 & - & - & KT310914 \\
\hline CHUNB63190 & 2 & Nova Xavantina (MT) & $-14.6733,-52.3531$ & 9 & KT310775 & - & - & KT310915 \\
\hline CHUNB63191 & 2 & Nova Xavantina (MT) & $-14.6733,-52.3531$ & 9 & KT310776 & - & KT310858 & - \\
\hline CHUNB63193 & 2 & Nova Xavantina (MT) & $-14.6733,-52.3531$ & 9 & KT310777 & - & KT310859 & KT310916 \\
\hline CHUNB52397 & 3 & Brasília (DF) & $-15.6968,-47.9250$ & 10 & KT310762 & KT310814 & KT310856 & - \\
\hline CHUNB60405 & 3 & Brasília (DF) & $-15.6968,-47.9250$ & 10 & KT310769 & - & - & KT310911 \\
\hline CHUNB60406 & 3 & Brasília (DF) & $-15.6968,-47.9250$ & 10 & KT310770 & - & - & - \\
\hline CHUNB60409 & 3 & Brasília (DF) & $-15.6968,-47.9250$ & 10 & KT310771 & - & - & KT310912 \\
\hline CHUNB60410 & 3 & Brasília (DF) & $-15.6968,-47.9250$ & 10 & KT310772 & - & - & - \\
\hline CHUNB59645 & 3 & Brasília (DF) & $-15.7579,-48.0599$ & 11 & KT310764 & - & - & - \\
\hline CHUNB59654 & 3 & Brasília (DF) & $-15.7579,-48.0599$ & 11 & - & - & - & - \\
\hline CHUNB59657 & 3 & Brasília (DF) & $-15.7579,-48.0599$ & 11 & KT310765 & - & - & - \\
\hline CHUNB59666 & 3 & Brasília (DF) & $-15.7579,-48.0599$ & 11 & KT310766 & - & - & KT310908 \\
\hline CHUNB946078 & 2 & Barra do Garças (MT) & $-15.8833,-52.2500$ & 12 & KT310778 & - & - & KT310917 \\
\hline CHUNB60345 & 3 & Brasília (DF) & $-15.9726,-47.9099$ & 13 & KT310767 & - & - & KT310909 \\
\hline CHUNB60346 & 3 & Brasília (DF) & $-15.9726,-47.9099$ & 13 & KT310779 & KT310816 & - & - \\
\hline
\end{tabular}




\begin{tabular}{|c|c|c|c|c|c|c|c|c|}
\hline CHUNB60348 & 3 & Brasília (DF) & $-15.9726,-47.9099$ & 13 & KT310768 & - & - & KT310910 \\
\hline UFG(PUB021) & 3 & Unaí (MG) & $-16.3575,-46.9061$ & 14 & KT310793 & KT310824 & KT310861 & - \\
\hline CHUNB43404 & 3 & Luziânia (GO) & $-16.5541,-48.0218$ & 15 & KT310750 & - & - & KT310896 \\
\hline CHUNB43405 & 3 & Luziânia (GO) & $-16.5541,-48.0218$ & 15 & KT310751 & KT310808 & KT310844 & KT310897 \\
\hline CHUNB26087 & 3 & Paracatu (MG) & $-17.1087,-46.8719$ & 16 & KT310734 & - & KT310838 & - \\
\hline CHUNB26088 & 3 & Paracatu (MG) & $-17.1087,-46.8719$ & 16 & KT310735 & - & - & KT310883 \\
\hline CHUNB26089 & 3 & Paracatu (MG) & $-17.1087,-46.8719$ & 16 & KT310736 & KT310803 & KT310839 & KT310884 \\
\hline CHUNB26092 & 3 & Paracatu (MG) & $-17.1087,-46.8719$ & 16 & KT310737 & KT310804 & KT310840 & KT310885 \\
\hline CHUNB26096 & 3 & Paracatu (MG) & $-17.1087,-46.8719$ & 16 & KT310738 & KT310805 & KT310841 & KT310886 \\
\hline CHUNB26099 & 3 & Paracatu (MG) & $-17.1087,-46.8719$ & 16 & KT310739 & - & - & KT310887 \\
\hline CHUNB26100 & 3 & Paracatu (MG) & $-17.1087,-46.8719$ & 16 & KT310740 & KT310806 & KT310842 & KT310888 \\
\hline CHUNB26106 & 3 & Paracatu (MG) & $-17.1087,-46.8719$ & 16 & KT310741 & - & - & KT310889 \\
\hline CHUNB26108 & 3 & Paracatu (MG) & $-17.1087,-46.8719$ & 16 & KT310742 & - & - & KT310890 \\
\hline CHUNB26110 & 3 & Paracatu (MG) & $-17.1087,-46.8719$ & 16 & KT310743 & KT310807 & KT310843 & KT310891 \\
\hline CHUNB26116 & 3 & Paracatu (MG) & $-17.1087,-46.8719$ & 16 & KT310744 & - & - & KT310892 \\
\hline CHUNB26121 & 3 & Paracatu (MG) & $-17.1087,-46.8719$ & 16 & KT310745 & - & - & KT310893 \\
\hline CHUNB26126 & 3 & Paracatu (MG) & $-17.1087,-46.8719$ & 16 & KT310746 & - & - & KT310894 \\
\hline CHUNB26129 & 3 & Paracatu (MG) & $-17.1087,-46.8719$ & 16 & KT310747 & - & - & KT310895 \\
\hline CHUNB26140 & 3 & Paracatu (MG) & $-17.1087,-46.8719$ & 16 & KT310748 & - & - & - \\
\hline CHUNB26146 & 3 & Paracatu (MG) & $-17.1087,-46.8719$ & 16 & KT310749 & - & - & - \\
\hline CHUNB44522 & 3 & Buritizeiro (MG) & $-17.2808,-45.1769$ & 17 & KT310752 & KT310809 & KT310845 & - \\
\hline MTR(LG856) & 3 & Santa Rita do Araguaia (MT) & $-17.3147,-53.2153$ & 18 & KT310783 & KT310818 & - & - \\
\hline MTR(LG865) & 4 & Santa Rita do Araguaia (MT) & $-17.3147,-53.2153$ & 18 & KT310784 & - & - & - \\
\hline UFRG56208 & 3 & Itiquira (MT) & $-17.3348,-53.8424$ & 19 & KT310794 & - & KT310862 & - \\
\hline MTR10635 & 4 & Sonora (MS) & $-17.6167,-54.9167$ & 20 & KT310791 & KT310822 & - & - \\
\hline MTR10637 & 4 & Sonora (MS) & $-17.6167,-54.9167$ & 20 & KT310792 & KT310823 & - & - \\
\hline MNRJ20981 & 4 & Corumbá (MS) & $-19.1998,-57.5846$ & 21 & KT310788 & - & - & KT310920 \\
\hline MNRJ20980 & 4 & Corumbá (MS) & $-19.1999,-57.5884$ & 21 & KT310787 & - & - & - \\
\hline
\end{tabular}

Table S2: Primers and PCR conditions used for the mitochondrial and nuclear genes.

\begin{tabular}{|l|l|l|l|}
\hline Primers & Gene & Sequences & Source \\
\hline ND2 LVT_MetF & ND2 & 5' AAGCTATTGGGCCCATACC 3' & Jeskova et al. 2009 Biol. J. Lin. Soc. 96:617-634 \\
\hline
\end{tabular}




\begin{tabular}{|c|c|c|c|}
\hline ND2 LVT_5617R & ND2 & 5' AAAGTGYTTGAGTTGCATTCA 3' & Jeskova et al. 2009 Biol. J. Lin. Soc. 96:617-634 \\
\hline ND2c_L5005 & ND2 & 5' AACCAAACCCAAACACGAAARATYAT 3' & Jennings et al. 2003 Syst. Biol. 52:757-780 \\
\hline NGFB-f2 & NGFB & 5' GATTATAGCGTTTCTGATYGGC 3' & Townsend et al. 2008 Mol. Phylogenet. Evol. 47:129-142 \\
\hline NGFB_r2 & NGFB & 5' CAAAGGTGTGTGTWGTGGTGC 3' & Townsend et al. 2008 Mol. Phylogenet. Evol. 47:129-142 \\
\hline PRLrF1 & PRL & 5' GACARYGARGACCAGCAACTRATGCC 3' & Townsend et al. 2008 Mol. Phylogenet. Evol. 47:129-142 \\
\hline PRLrR3 & PRL & 5' GACYTTGTGRACTTCYACRTAATCCAT 3' & Townsend et al. 2008 Mol. Phylogenet. Evol. 47:129-142 \\
\hline NKTRr18 & NKTR & 5' CTYCTDGAYCGACTTCTTGAGTGACT 3' & Townsend et al. 2011 Mol. Phylogenet. Evol 61: 363-380. \\
\hline NKTRf19 & NKTR & 5'GATGACATGGAGATYTGYACTCC 3' & Townsend et al. 2011 Mol. Phylogenet. Evol 61: 363-380. \\
\hline
\end{tabular}

PCR profile (nuclear): $94^{\circ} / 5: 00 \mathrm{~min}$; (94\% $/ 0: 30 \mathrm{~min} ; 52^{\circ} / 0: 45 \mathrm{~min} ; 72^{\circ} / 1: 00 \mathrm{~min}$ ) $\times 32 ; 72^{\circ} / 5 \mathrm{~min}$

PCR profile (mitochondrial): $96 / 6 \mathrm{~min},\left(96^{\circ} / 0: 45 \mathrm{~min}, 56^{\circ} / 0: 45 \mathrm{~min}, 72^{\circ} / 1: 30 \mathrm{~min}\right) \times 30 ; 72^{\circ} / 6 \mathrm{~min}$

Table S3. Percentage sequence divergence in three nuclear genes (NGFB, NKTR, and PRL) based on the number of base differences per site from averaging over all sequence pairs between lineages.

\begin{tabular}{|l|l|l|l|l|l|}
\hline NGFB & Lineage 1 & Lineage 2 & Lineage 3 & Lineage 4 & Lineage 5 \\
\hline Lineage 1 & 0 & & & & \\
\hline Lineage 2 & 0.4 & 0 & & & \\
\hline Lineage 3 & 1.1 & 1.4 & 0 & & \\
\hline Lineage 4 & - & - & - & 0 & \\
\hline Lineage 5 & 2.5 & 2.8 & 2 & - & 0 \\
\hline NKTR & Lineage 1 & Lineage 2 & Lineage 3 & Lineage 4 & Lineage 5 \\
\hline Lineage 1 & 0 & & & & \\
\hline Lineage 2 & 0.3 & 0 & & & \\
\hline Lineage 3 & 2 & 2.1 & 0 & & \\
\hline Lineage 4 & 1.2 & 1.3 & 2 & 0 & \\
\hline Lineage 5 & 1.3 & 1.3 & 2.6 & 2.2 & 0 \\
\hline PRL & Lineage 1 & Lineage 2 & Lineage 3 & Lineage 4 & Lineage 5 \\
\hline Lineage 1 & 0 & & & & \\
\hline Lineage 2 & 1.2 & 0 & & & \\
\hline Lineage 3 & 1.2 & 1.2 & 0 & & \\
\hline Lineage 4 & 1.3 & 1.3 & 0.7 & 0 & \\
\hline Lineage 5 & 0.9 & 0.6 & 0.9 & 1.1 & 0 \\
\hline
\end{tabular}




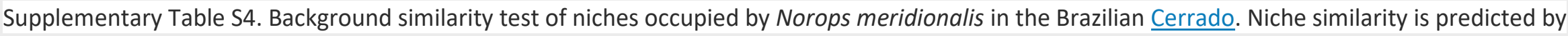
the hypothesis of niche conservatism. 'Null' indicates the 1 ! (1 ! a / 2) and (1 ! a / 2) quantiles of the null distribution obtained by 100 randomizations and used to evaluate significance of observed $D$ and I statistics. The numbers of georeferenced localities within each region was: Lineage 3: 10 sites, Lineage 2: 7 sites.

\begin{tabular}{|l|l|l|l|l|l|l|l|}
\hline Pairwise comparison & & $\begin{array}{l}\text { Schoener's D } \\
\text { statistic }\end{array}$ & & & $\begin{array}{l}\text { Similarity } \\
\text { statistic I }\end{array}$ & \\
\hline Model X & Model Y & D & $\begin{array}{l}\text { X vs. random Y } \\
\text { (null) }\end{array}$ & Y vs. random X (null) & I & $\begin{array}{l}\text { X vs. random Y } \\
\text { (null) }\end{array}$ & Y vs. random X (null) \\
\hline Lineage 3 & Lineage 2 & 0.533 & $0.331,0.471$ & $0.418,0.546$ & 0.799 & $0.603,0.730$ & $0.695,0.803$ \\
\hline
\end{tabular}




\section{References}

Akaike, $1974 \mathrm{H}$. Akaike A new look at the statistical model identification IEEE. Trans. Automat.

Contr., 19 (1974), pp. 716-723

Avise, 2000 J.C. Avise Phylogeography: The History and Formation of Species Harvard University Press (2000)

Bacon et al., 2015 C.D. Bacon, D. Silvestro, C. Jaramillo, B.T. Smith, P. Chakrabarty, A. Antonelli Biological

evidence supports an early and complex emergence of the Isthmus of Panama Proc. Natl. Acad. Sci.

USA, 112 (2015), pp. 6110-6115

Barton and Wilson, 1995 N. Barton, I. Wilson Genealogies and geography Philos. Trans. Soc. B, 349 (1995),

pp. 49-59

Bergsten et al., 2012

J. Bergsten, D.T. Bilton, T. Fujisawa, M. Elliott, M.T. Monaghan, M. Balke, L. Hendrich, J. Geijer, J. Herrma $\mathrm{nn}, \mathrm{G}$. N. Foster The effect of geographical scale of sampling on DNA barcoding Syst. Biol., 6 (2012), pp. 851-869

Bielejec et al., 2011 F. Bielejec, A. Rambaut, M.A. Suchard, P. Lemey SPREAD: spatial phylogenetic reconstruction of evolutionary dynamics Bioinformatics, 27 (2011), pp. 2910-2912

Calsbeek et al., 2007 R. Calsbeek, T.B. Smith, C. Bardeleben Intraspecific variation in Anolis sagrei mirrors the adaptive radiation of Greater Antillean anoles Biol. J. Linn. Soc., 90 (2007), pp. 189-199

Castañeda and De Queiroz, 2011 M.D.R. Castañeda, K. De Queiroz Phylogenetic relationships of the Dactyloa clade of Anolis lizards based on nuclear and mitochondrial DNA sequence data Mol. Phylogenet. Evol., 61 (2011), pp. 784-800

Castañeda and De Queiroz, 2013 M.D.R. Castañeda, K. De Queiroz Phylogeny of the Dactyloa clade of Anolis lizards: new insights from combining morphological and molecular data Bull. Mus. Comp. Zool., 160 (2013), pp. 345-398

Colli et al., 2005 Colli, G., Scariot, A., Souza-Silva, J., Felfili, J., 2005. As origens e a diversificação da herpetofauna do Cerrado. Cerrado: Ecologia, Biodiversidade e Conservação, Ministério do Meio Ambiente, Brasília, pp. 247-264.

Corander et al., 2006 Corander, J., Marttinen, P., Sirén, J., Tang, J., 2006. BAPS: Bayesian Analysis of Population Structure, Manual v. 4.1. Department of Mathematics and Statistics, University of Helsinki.

Costa et al., 2013 B.M. Costa, D.L. Pantoja, M.C.M. Vianna, G.R. Colli Direct and short-term effects of fire on lizard assemblages from a Neotropical Savanna hotspot J. Herpetol., 47 (2013), pp. 502-510

D’Angiolella et al., 2011 A.B. D'Angiolella, T. Gamble, T.C. Avila-Pires, G.R. Colli, B.P. Noonan, L.J. Vitt Anolis chrysolepis Duméril and Bibron, 1837 (Squamata: Iguanidae), revisited: molecular phylogeny and taxonomy of the Anolis chrysolepis species group Bull. Mus. Comp. Zool., 160 (2011), pp. 35-63

Darriba et al., 2012 D. Darriba, G.L. Taboada, R. Doallo, D. Posada JModelTest 2: more models, new heuristics and parallel computing Nat. Methods, 9 (2012), p. 772

Domingos et al., 2014

F.M. Domingos, R.J. Bosque, J. Cassimiro, G.R. Colli, M.T. Rodrigues, M.G. Santos, L.B. Beheregaray Out of the deep: cryptic speciation in a Neotropical gecko (Squamata, Phyllodactylidae) revealed by species delimitation methods Mol. Phylogenet. Evol., 80 (2014), pp. 113-124

Drummond and Rambaut, 2007 A.J. Drummond, A. Rambaut BEAST: bayesian evolutionary analysis by sampling trees BMC Evol. Biol., 7 (2007), p. 214

Duforet-Frebourg and Blum, 2014 N. Duforet-Frebourg, M.G. Blum Nonstationary patterns of isolation-bydistance: inferring measures of local genetic differentiation with bayesian kriging Evolution, 68 (2014), pp. $1110-1123$

Ersts, 2011 Ersts, P., 2011. Geographic Distance Matrix Generator (version 1.2.3). American Museum of Natural History. Center for Biodiversity and Conservation.

Felsenstein, 1989 J. Felsenstein Phylip (version 3.2): phylogeny inference package Cladistics, 5 (1989), pp. 164166 
Gainsbury and Colli, 2003 A.M. Gainsbury, G.R. Colli Lizard assemblages from natural Cerrado enclaves in southwestern Amazonia: the role of stochastic extinctions and isolation Biotropica, 35 (2003), pp. 503519

Gainsbury and Colli, 2014 A.M. Gainsbury, G.R. Colli Effects of abandoned Eucalyptus plantations on lizard communities in the Brazilian Cerrado Biodivers. Conserv., 23 (2014), pp. 3155-3170

Gamble et al., 2012 T. Gamble, G.R. Colli, M.T. Rodrigues, F.P. Werneck, A.M. Simons Phylogeny and cryptic diversity in geckos (Phyllopezus; Phyllodactylidae; Gekkota) from South America's open biomes Mol. Phylogenet. Evol., 62 (2012), pp. 943-953

Garda and Cannatella, 2007 A.A. Garda, D.C. Cannatella Phylogeny and biogeography of paradoxical frogs (Anura, Hylidae, Pseudae) inferred from $12 \mathrm{~S}$ and 165 mitochondrial DNA Mol. Phylogenet. Evol., 44 (2007), pp. 104-114

Garrick, 2010 R. Garrick Montane refuges and topographic complexity generate and maintain invertebrate biodiversity: recurring themes across space and time J. Insect Conserv., 15 (2010), pp. 469-478

Ghalambor et al., 2006 C.K. Ghalambor, R.B. Huey, P.R. Martin, J.J. Tewksbury, G. Wang Are mountain passes higher in the tropics? Janzen's hypothesis revisited Integr. Comp. Biol., 46 (2006), pp. 5-17

Giugliano et al., 2013 L.G. Giugliano, C. de Campos Nogueira, P.H. Valdujo, R.G. Collevatti, G.R. Colli Cryptic diversity in South American Teiinae (Squamata, Teiidae) lizards Zool. Scr., 42 (2013), pp. 473-487

Glor et al., 2001 R. Glor, L. Vitt, A. Larson A molecular phylogenetic analysis of diversification in Amazonian Anolis lizards Mol. Ecol., 10 (2001), pp. 2661-2668

Gómez-Rodríguez et al., 2014 C. Gómez-Rodríguez, A. Baselga, J.J. Wiens Is diversification rate related to climatic niche width? Glob. Ecol. Biogeogr., 24 (2014), pp. 383-395

Guarnizo and Cannatella, 2013 C.E. Guarnizo, D.C. Cannatella Genetic divergence within frog species is greater in topographically more complex regions J. Zool. Syst. Evol. Res., 51 (2013), pp. 333-340

Heibl and Calenge, 2011 Heibl, C., Calenge, C., 2011. Phyloclim: inTegrating Phylogenetics and Climatic Niche Modelling. R Package. (accessed 20.09.10).

Hertz et al., 2013 P.E. Hertz, Y. Arima, A. Harrison, R.B. Huey, J.B. Losos, R.E. Glor Asynchronous evolution of physiology and morphology in Anolis lizards Evolution, 67 (2013), pp. 2101-2113

Hijmans et al., 2005 R. Hijmans, S. Cameron, J. Parra, P. Jones, A. Jarvis Very high resolution interpolated climate surfaces for global land areas Int. J. Climatol., 25 (2005), pp. 1965-1978

Knouft et al., 2006 J.H. Knouft, J.B. Losos, R.E. Glor, J.J. Kolbe Phylogenetic analysis of the evolution of the niche in lizards of the Anolis sagrei group Ecology, 87 (2006), pp. 29-38

Langstroth, 2006 Langstroth, R.P., 2006. Notas sobre Anolis meridionalis Boettger, 1885 (Squamata: Iguania: Polychrotidae) en Bolivia y comentarios sobre Anolis steinbachi. Kempffiana 2.

Leaché and Fujita, 2010 A.D. Leaché, M.K. Fujita Bayesian species delimitation in West African forest geckos (Hemidactylus fasciatus) Proc. Roy. Soc. B, 277 (2010), pp. 3071-3077

Lemey et al., 2010 P. Lemey, A. Rambaut, J.J. Welch, M.A. Suchard Phylogeography takes a relaxed random walk in continuous space and time Mol. Biol. Evol., 27 (2010), pp. 1877-1885

Losos, 2008 J.B. Losos Phylogenetic niche conservatism, phylogenetic signal and the relationship between phylogenetic relatedness and ecological similarity among species Ecol. Lett., 11 (2008), pp. 995-1003

Losos, 2009 J.B. Losos Lizards in an Evolutionary Tree: Ecology and Adaptive Radiation of Anoles Univ of California Press (2009)

Losos et al., 2003 J.B. Losos, M. Leal, R.E. Glor, K. de Queiroz, P.E. Hertz, L.R. Schettino, A.C. Lara, T.R. Jackman, A. Larson Niche lability in the evolution of a Caribbean lizard community Nature, 424 (2003), pp. 542-545

Lundberg et al., 1998 J.G. Lundberg, L.G. Marshall, J. Guerrero, B. Horton, M. Malabarba, F. Wesselingh The stage for Neotropical fish diversification: a history of tropical South American rivers Phylogeny Classif. Neotrop. Fish. (1998), pp. 13-48

Macey et al., 1998 J.R. Macey, J.A. Schulte II, N.B. Ananjeva, A. Larson, N. RastegarPouyani, S.M. Shammakov, T.J. Papenfuss Phylogenetic relationships among agamid lizards of 
the Laudakia caucasia species group: testing hypotheses of biogeographic fragmentation and an area cladogram for the Iranian plateau Mol. Phylogenet. Evol., 10 (1998), pp. 118-131

Machado et al., 2014 T. Machado, V.X. Silva, M.J.d.J. Silva Phylogenetic relationships within Bothrops neuwiedi group (Serpentes, Squamata): geographically highly-structured lineages, evidence of introgressive hybridization and Neogene/Quaternary diversification Mol. Phylogenet. Evol., 71 (2014), pp. 1-14

Maciel et al., 2010 N.M. Maciel, R.G. Collevatti, G.R. Colli, E.F. Schwartz Late Miocene diversification and phylogenetic relationships of the huge toads in the Rhinella marina (Linnaeus, 1758) species group (Anura: Bufonidae) Mol. Phylogenet. Evol., 57 (2010), pp. 787-797

Magalhaes et al., 2014 I.L. Magalhaes, U. Oliveira, F.R. Santos, T.H. Vidigal, A.D. Brescovit, A.J. Santos Strong spatial structure, Pliocene diversification and cryptic diversity in the Neotropical dry forest spider Sicarius cariri Mol. Ecol., 23 (2014), pp. 5323-5336

Manni et al., 2004 F. Manni, E. Guerard, E. Heyer Geographic patterns of (genetic, morphologic, linguistic) variation: how barriers can be detected by using Monmonier's algorithm Hum. Biol., 76 (2004), pp. $173-190$

Montes et al., 2015C. Montes, A. Cardona, C. Jaramillo, A. Pardo, J. Silva, V. Valencia, C. Ayala, L. PérezAngel, L. Rodriguez-Parra, V. Ramirez Middle miocene closure of the Central American seaway Science, 348 (2015), pp. 226-229

Motte and Cacciali, 2009 M. Motte, P. Cacciali Descripción de un neotipo para Anolis meridionalis Boettger, 1885 (Sauria: Polychrotidae) Cuad. Herpetol., 23 (2009), pp. 19-24

Mulch et al., 2010 A. Mulch, C.E. Uba, M.R. Strecker, R. Schoenberg, C.P. Chamberlain Late Miocene climate variability and surface elevation in the central Andes Earth Planet. Sci. Lett., 290 (2010), pp. 173-182

Myers et al., 2000 N. Myers, R. Mittermeier, C. Mittermeier, G. da Fonseca, J. Kent Biodiversity hotspots for conservation priorities Nature, 403 (2000), pp. 853-858

Navas, 2002 C. Navas Herpetological diversity along Andean elevational gradients: links with physiological ecology and evolutionary physiology Compos. Biochem. Phys. A, 133 (2002), pp. 469-485

Nicholson et al., 2014 K. Nicholson, B. Crother, C. Guyer, J. Savage Anole classification: a response to Poe Zootaxa, 3814 (2014), pp. 109-120

Nicholson et al., 2012 K.E. Nicholson, B.I. Crother, C. Guyer, J.M. Savage It is time for a new classification of anoles (Squamata: Dactyloidae) Zootaxa, 3477 (2012), p. 88

Nicholson et al., 2005 K.E. Nicholson, R.E. Glor, J.J. Kolbe, A. Larson, S. Blair Hedges, J.B. Losos Mainland colonization by island lizards J. Biogeogr., 32 (2005), pp. 929-938

Nicholson et al., 2006 K.E. Nicholson, A. Mijares-Urrutia, A. Larson Molecular phylogenetics of the Anolis onca series: a case history in retrograde evolution revisited J. Exp. Zool. Part A, 306 (2006), pp. 450-459

Nogueira et al., 2010 C. Nogueira, G.R. Colli, G. Costa, R.B. Machado Diversidade de répteis Squamata e evolução do conhecimento faunístico no Cerrado I.R. Diniz, J. Marinho-

Filho, R.B. Machado, R.B. Cavalcanti (Eds.), Cerrado: conhecimento científico quantitativo como subsídio para ações de conservação, Editora UnB, Brasília (2010), pp. 333-375

Nogueira et al., 2011 C. Nogueira, S. Ribeiro, G.C. Costa, G.R. Colli Vicariance and endemism in a Neotropical savanna hotspot: distribution patterns of Cerrado squamate reptiles J. Biogeogr., 38 (2011), pp. 19071922

Nogueira et al., 2005 C. Nogueira, P.H. Valdujo, F.G. França Habitat variation and lizard diversity in a Cerrado area of Central Brazil Stud. Neotrop. Fauna Environ., 40 (2005), pp. 105-112

Phillips et al., 2010 Phillips, S., Dudík, M., Schapire, R., 2010. Maxent Software for Species Habitat Modeling, Version 3.3. 1.

Pinheiro et al., 2013 F. Pinheiro, S. Cozzolino, F. Barros, T.M. Gouveia, R.M. Suzuki, M.F. Fay, C. Palma-Silva Phylogeographic structure and outbreeding depression reveal early stages of reproductive isolation in the Neotropical orchid Epidendrum denticulatum Evolution, 67 (2013), pp. 2024-2039

Poe, 2013 S. Poe 1986 Redux: new genera of anoles (Squamata: Dactyloidae) are unwarranted Zootaxa, 3626 (2013), pp. 295-299 
Prado et al., 2012 C. Prado, C.F. Haddad, K.R. Zamudio Cryptic lineages and Pleistocene population expansion in a Brazilian Cerrado frog Mol. Ecol., 21 (2012), pp. 921-941

Prates et al., 2014 I. Prates, M.T. Rodrigues, P.R. Melo-Sampaio, A.C. Carnaval Phylogenetic relationships of Amazonian anole lizards (Dactyloa): taxonomic implications, new insights about phenotypic evolution and the timing of diversification Mol. Phylogenet. Evol., 82 (2014), pp. 258-268

Rambaut et al., 2014 Rambaut, A., Suchard, M., Xie, D., Drummond, A., 2014. Tracer v1.6. $<$ http://beast.bio.ed.ac.uk/Tracer>.

Ramos et al., 2007 A.C.S. Ramos, J.P. Lemos-Filho, R.A. Ribeiro, F.R. Santos, M.B. Lovato Phylogeography of the tree Hymenaea stigonocarpa (Fabaceae: Caesalpinioideae) and the influence of Quaternary climate changes in the Brazilian Cerrado Ann. Bot., 100 (2007), pp. 1219-1228

Rannala and Yang, 2013 B. Rannala, Z. Yang Improved reversible jump algorithms for Bayesian species delimitation Genetics, 194 (2013), pp. 245-253

Recoder et al., 2014 R.S. Recoder, F.P. Werneck, M. Teixeira, G.R. Colli, J.W. Sites, M.T. Rodrigues Geographic variation and systematic review of the lizard genus Vanzosaura (Squamata, Gymnophthalmidae), with the description of a new species Zool. J. Linn. Soc. Lond., 171 (2014), pp. 206-225

Ricklefs, 1987 R.E. Ricklefs Community diversity: relative roles of local and regional processes Science, 235 (1987), pp. 167-171

Ronquist and Huelsenbeck, 2003 F. Ronquist, J.P. Huelsenbeck MrBayes 3: Bayesian phylogenetic inference under mixed models Bioinformatics, 19 (2003), p. 1572

Santos et al., 2014 M.G. Santos, C. Nogueira, L.G. Giugliano, G.R. Colli Landscape evolution and phylogeography of Micrablepharus atticolus (Squamata, Gymnophthalmidae), an endemic lizard of the Brazilian Cerrado J. Biogeogr. (2014), pp. 1506-1519

Stamatakis, 2006 A. Stamatakis RAxML-VI-HPC: maximum likelihood-based phylogenetic analyses with thousands of taxa and mixed models Bioinformatics, 22 (2006), p. 2688

Tamura et al., 2011 K. Tamura, D. Peterson, N. Peterson, G. Stecher, M. Nei, S. Kumar MEGA5: molecular evolutionary genetics analysis using maximum likelihood, evolutionary distance, and maximum parsimony methods Mol. Biol. Evol., 28 (2011), pp. 2731-2739

Thorpe et al., 2010 R.S. Thorpe, Y. Surget-Groba, H. Johansson Genetic tests for ecological and allopatric speciation in anoles on an island archipelago PLoS Genet., 6 (2010), p. e1000929

Tollis et al., 2012 M. Tollis, G. Ausubel, D. Ghimire, S. Boissinot Multi-locus phylogeographic and population genetic analysis of Anolis carolinensis: historical demography of a genomic model species PLoS ONE, 7 (2012), p. e38474

Uba et al., 2006 C.E. Uba, C. Heubeck, C. Hulka Evolution of the late Cenozoic Chaco foreland basin, southern Bolivia Basin Res., 18 (2006), pp. 145-170

Vanzolini, 1976 P. Vanzolini On the lizards of a Cerrado-Caatinga contact: evolutionary and zoogeographical implications (Sauria) Pap. Avulsos Zool., 29 (1976), pp. 111-119

Vanzolini and Williams, 1970 P.E. Vanzolini, E.E. Williams South American anoles: the geographic differentiation and evolution of the Anolis chrysolepis species group (Sauria, Iguanidae) Arq. Zool., 19 (1970), pp. 1176

Vitt, 1991 L.J. Vitt An introduction to the ecology of Cerrado lizards J. Herpetol. (1991), pp. 79-90

Vitt and Caldwell, 1993 L.J. Vitt, J.P. Caldwell Ecological observations on Cerrado lizards in Rondônia, Brazil J. Herpetol. (1993), pp. 46-52

Wade and McCauley, 1988 M.J. Wade, D.E. McCauley Extinction and recolonization: their effects on the genetic differentiation of local populations Evolution (1988), pp. 995-1005

Wang and Bradburd, 2014 I.J. Wang, G.S. Bradburd Isolation by environment Mol. Ecol., 23 (2014), pp. 56495662

Warren et al., 2008 D.L. Warren, R.E. Glor, M. Turelli Environmental niche equivalency versus conservatism: quantitative approaches to niche evolution Evolution, 62 (2008), pp. 2868-2883 
Werneck et al., 2009 F.d.P. Werneck, L.G. Giugliano, R.G. Collevatti, G.R. Colli Phylogeny, biogeography and evolution of clutch size in South American lizards of the genus Kentropyx (Squamata: Teiidae) Mol. Ecol., 18 (2009), pp. 262-278

Werneck, 2011 F.P. Werneck The diversification of eastern South American open vegetation biomes: historical biogeography and perspectives Quatern. Sci. Rev., 30 (2011), pp. 1630-1648

Werneck et al., 2012a F.P. Werneck, T. Gamble, G.R. Colli, M.T. Rodrigues, J.W. Sites Jr Deep diversification and long-term persistence in the South American "Dry Diagonal": integrating continent-wide phylogeography and distribution modelling of geckos Evolution, 66 (2012), pp. 3014-3034

Werneck et al., 2012d F.P. Werneck, C. Nogueira, G.R. Colli, J.W. Sites, G.C. Costa Climatic stability in the Brazilian Cerrado: implications for biogeographical connections of South American savannas, species richness and conservation in a biodiversity hotspot J. Biogeogr., 39 (2012), pp. 1695-1706

Wiens, 1989 J.A. Wiens Spatial scaling in ecology Funct. Ecol., 3 (1989), pp. 385-397

Wiens, 2004 J.J. Wiens Speciation and ecology revisited: phylogenetic niche conservatism and the origin of species Evolution, 58 (2004), pp. 193-197

Wiens and Graham, 2005 J.J. Wiens, C.H. Graham Niche conservatism: integrating evolution, ecology, and conservation biology Annu. Rev. Ecol. Evol. Syst., 36 (2005), pp. 519-539

Williams, 1969 E.E. Williams The ecology of colonization as seen in the zoogeography of anoline lizards on small islands Quart. Rev. Biol. (1969), pp. 345-389

Yang and Rannala, 2010 Z. Yang, B. Rannala Bayesian species delimitation using multilocus sequence data Proc. Natl. Acad. Sci. USA, 107 (2010), pp. 9264-9269 